\title{
SOSTENIBILIDAD DE DISTINTAS FORMAS DE CRECIMIENTO EN CIUDADES EMERGENTES SUDAMERICANAS \\ Experiencia colaborativa para la medición comparativa de indicadores aplicados al hábitat urbano local
}

\author{
Autores: GIGLIO, Mónica Adriana; PUENTES, Elquin y HOLZER Werther. \\ Filiación Institucional: Universidad de Buenos Aires, Universidad Antonio Nariño, Univ. Federal Fluminense \\ Directora. Dra. Arq. Mónica Adriana Giglio. documentosgiglio@yahoo.com.ar
}

\section{RESUMEN}

En los últimos veinte años, el crecimiento de la huella urbana en América Latina, evidencia una relación insostenible entre la extensión de la mancha urbana y el crecimiento poblacional, observándose un mayor consumo de suelo por habitante. Frecuentemente, suelos aptos para cultivo son ocupados por urbanizaciones de lujo con baja densidad y alta segregación social. También se ocupan zonas de riesgo ambiental con urbanizaciones marginales y los sectores medios, construyen sus viviendas en parcelas sin suficientes servicios. La investigación plantea una propuesta colaborativa entre investigadores de Colombia, Brasil y Argentina para procesar y divulgar los resultados entre los agentes decisores del proceso de planificación. Para lograr este objetivo, se propone aplicar los indicadores de sostenibilidad urbana propuestos por la Agencia de Ecología Urbana de Barcelona, evaluando comparativamente las distintas formas de crecimiento urbano que se desarrollan en el contexto de latinoamericano y proponer una adaptación de los mismos a la realidad regional.

Palabras clave: Crecimiento, Sostenibilidad, Hábitat.

\section{ABSTRACT}

The expansion of the urban footprint in Latin America over the past 20 years reveals an untenable relationship between urban sprawl and population growth, with an increase in land use per capita. Tracts of arable land often are occupied by low-density, highly socially segregated luxury developments.

Environmental risk zones also contain marginal housing, and middle-income homes are built on sites without adequate infrastructure.

The proposed study involves a collaboration between researchers from Colombia, Brazil and Argentina to process the results and share them with decision-makers in the planning process.

To achieve this objective, the researchers plan to use the urban sustainability indicators put forth by the Urban Ecology Agency of Barcelona to perform a comparative evaluation of different forms of urban growth taking place in Latin America, and propose ways to adapt them to the realities of the region.

Key words: Growth - Sustainability - Habitat 


\section{ESTADO ACTUAL DE CONOCIMIENTO SOBRE EL TEMA}

En los últimos años, el debate entre la ciudad compacta europea y la ciudad dispersa americana ha sido ampliamente discutido y registrado, pero no deja de tener actualidad, especialmente ante el desafió que nos plantea la nueva agenda urbana para medir la sostenibilidad de los procesos de crecimiento de las ciudades. La utilización de indicadores, no permite evaluar la huella urbana que dejan los distintos modelos de urbanización y comparar la eficiencia de cada uno.

Para planificar las ciudades, la ordenación del territorio clásica, se ha basado en el control de los usos del suelo y en la definición de los límites del aprovechamiento materializable, más que en la evaluación del potencial territorial que permita una mejora en los niveles de desarrollo y de calidad de vida (Farinós, 2009, p18).

La idea de crecimiento, lleva implícito un cambio que se aprecia con el paso del tiempo. Desde esta óptica, puede verse que en el libro "De ciudades emergentes a ciudades sostenibles. Comprendiendo y proyectando las metrópolis del siglo veintiuno." (Terraza, 2016), se plantea la situación de las ciudades intermedias latinoamericanas diciendo que "... está ocurriendo un proceso similar al acaecido durante la segunda mitad del siglo pasado: están creciendo a tasas considerablemente mayores que las megalópolis urbanas ... en estas ciudades vive el $75 \%$ de la población mundial ... En el mundo hay más de 4.000 asentamientos menores a 500.000 habitantes, de los cuales un $60 \%$ están en regiones en desarrollo como Latinoamérica y el Caribe, donde la tasa de urbanización paso de ser del $41 \%$ en 1950 al $79 \%$ en 2010. En dicha bibliografía, se describe el proceso de cambio, pasando de un crecimiento orgánico a la ciudad emergente que se está produciendo, y se proponen lineamientos para que este proceso se encuadre dentro de los indicadores de una ciudad sostenible.

Para abordar la problemática de la expansión urbana, nos centraremos en distinguir las distintas formas de crecimiento, basados en la metodología propuesta por Solá Morales i Rubió (en Solá Morales i Rubió, 1997) que parte de analizar la forma en que se combinan tres variables: Urbanización, Parcelación y Edificación, para identificar los distintos tipos de crecimiento: Ensanche, Suburbano, Ciudad Jardín, Polígono y Urbanización Marginal. Una de las hipótesis principales de esta investigación, es que las formas que Solá Morales identificó para Barcelona, pueden aplicarse en Buenos Aires, para casos de crecimiento por extensión, y para incorporar el tema de la incidencia de los indicadores urbanísticos establecidos por la normativa, en la configuración del tejido de la ciudad.

Esta forma de interpretar la realidad urbana, plantea la identificación de patrones de conformación espacial. En general, el resultado evidente de esta lectura, se establece mediante un lenguaje material, derivado del análisis de las formas de crecimiento y ocupación del territorio. Esta forma de problematizar la realidad, no obstante, no debe descuidar que, tras esa evidencia física, siempre subyace un espesor de capas históricas y de sucesivos acontecimientos culturales que, justamente, son los que acaban por constituir esas huellas físicas.

Quizás, la forma más pertinente de enfocar esta cuestión, implique reconocer que el espacio urbano es la expresión socio-territorial de una serie de procesos de producción que son los que finalmente determinan la estructura resultante.

El desafío que propone el presente proyecto, plantea tratar de responder desde una propuesta de construcción colaborativa, cuáles resultarían los indicadores adecuados para verificar los rasgos de la estructura socio-territorial desde una perspectiva de los países sudamericanos, basados en las más avanzadas metodologías para la medición de indicadores para el crecimiento sostenible.

El conocimiento de la diferencia entre las mediciones de los indicadores de la situación urbana existente, y los estándares deseables para alcanzar la sostenibilidad de los procesos de crecimiento, permite plantear las estrategias para alcanzar las metas deseables.

Como parámetro para definir las metas a alcanzar, se toman como referencia, tanto los objetivos de la Agenda 2030 para el Desarrollo Sostenible como los 17 Objetivos del Desarrollo Sostenible de la ONU, dado que en ambos documentos se reconocen a la igualdad y a la sostenibilidad como sus principios rectores y universales. 


\section{OBJETIVOS E HIPÓTESIS DE LA INVESTIGACIÓN}

\section{Objetivo General}

Identificar, observar y comparar distintas formas de crecimiento urbano a partir de indicadores adaptados para países de América Latina, con la finalidad de evaluar la sostenibilidad del crecimiento y proponer lineamientos para optimizar su mejoramiento y control.

\section{Objetivos Específicos}

1- Identificar, calificar y seleccionar indicadores que se adapten a las condiciones de contexto, de las ciudades latinoamericanas involucradas en el proyecto, tomando como punto de partida la experiencia de la Agencia de Ecología Urbana de Barcelona para esa ciudad.

2- Observar distintas formas de Unidades Territoriales de Crecimiento (UTC), definidas por su proceso de urbanización, a partir de la metodología propuesta por Solá Morales.

3- Comparar las UTC analizadas en distintos países mediante indicadores y procedimientos pautados por el conjunto de las universidades participantes del Proyecto, teniendo en cuenta las particularidades y aportes locales.

4- Proponer lineamientos acciones y metodología que permitan optimizar la sostenibilidad del crecimiento urbano de nuestras ciudades, transfiriendo los resultados de este trabajo a los decisores de la planificación local de cada ciudad.

\section{Hipótesis iniciales}

Los indicadores de la Agencia de Ecología Urbana de Barcelona, formulados por Salvador Rueda pueden ser aplicados en Latinoamérica, si se realiza un proceso de adaptación a las particularidades, condiciones y circuitos de producción y ocupación del hábitat local.

Las experiencias realizadas sobre cuatro casos identificados mediante la aplicación del marco teórico propuesto por Solá Morales en el Área Metropolitana de Buenos Aires, son potencialmente replicables en otros países o regiones del mismo país.

Las formas de crecimiento definidas por Solá Morales (en Solá Morales 1997), se encuentran en distintas ciudades con lógicas similares y sirven como validación del marco teórico propuesto, así como para identificar los casos de análisis.

Partir de un mismo marco teórico para definir las UTC y unificar el estudio y elaboración de la metodología para abordar los indicadores de sostenibilidad de crecimiento, permiten crear las condiciones adecuadas para el análisis de problemáticas similares en territorios diversos, así como obtener un estudio comparativo que informe sobre la situación relativa de cada caso alcanzado.

A partir de la adaptación colaborativa de las metodologías tomadas como marco, pueden definirse los lineamientos aplicables localmente.

\section{METODOLOGÍA}

Por las características del tema abordado, la investigación se plantea con un perfil netamente aplicada, en tanto busca obtener cuantificaciones (y cualificaciones) que tengan una aplicación concreta y superador a de la problemática abordada. En este sentido la metodología se plantea concreta en términos de su marco teórico, a la vez que flexible a realidades alternas de cada región para su aplicación.

Se utilizará fuentes de información primarias (trabajo de campo, planimetrías, encuestas a informantes claves, etc.) y secundarias (libros o artículos de otros trabajos cercanos al tema).

De la exploración bibliográfica realizada en etapas anteriores de la investigación, se han seleccionado algunos aportes instrumentales a tener en cuenta para abordar la construcción de indicadores, destacándose la siguiente bibliografía: Para la delimitación de las Unidades Territoriales de Crecimiento (UTC) se aplicarán los indicadores de Solá Morales y Rubió (Solá Morales, 1997), definidos en el libro "Las Formas de Crecimiento Urbano", que permiten caracterizar las unidades de estudio con un mismo criterio y base teórica.

Para la definición de los indicadores de sostenibilidad que se utilizarán para evaluar las diferentes UTC, se empleará la documentación producida por la Agencia de Ecología Urbana de Barcelona empleados por Salvador Rueda. 


\subsection{Secuencia metodológica}

En la metodología propuesta, se plantea una forma flexible de trabajo, donde los investigadores de las tres universidades integrantes del proyecto que se expone, definen sus cronogramas de trabajo de acuerdo a los términos y condiciones de cada programa de financiamiento, pactándose reuniones virtuales periódicas de coordinación. Inicialmente se parte de la experiencia realizada por la UBA y luego se irán reformulando los indicadores, de acuerdo a las posibilidades de implementación y a las experiencias de aplicación.

Dentro de la mecánica de funcionamiento está previsto que se podrán incorporar nuevos grupos de investigación, siguiendo las siguientes etapas básicas:

a- $\quad$ Selección de la ciudad o municipio. Constituirá el área de referencia de las Unidades Territoriales de Crecimiento (UTC). Se definirán los indicadores que las caractericen y la evolución del crecimiento durante el período de estudio (1990-2010) Las primeras tres ciudades seleccionadas son: Usme (Colombia), Maricá (Brasil) y Del Pilar (Argentina).

b- Identificación de las UTC. En base a los indicadores urbanos definidos por Solá Morales (Urbanización, Parcelamiento y Edificación) con las adaptaciones realizadas por el grupo UBA.

c- $\quad$ Aplicación de los indicadores de sostenibilidad. Inicialmente se parte de la propuesta de Salvador Rueda, con las adaptaciones que se vayan definiendo en forma colaborativa, de acuerdo a las necesidades y posibilidades locales.

d- $\quad$ Evaluación del aprovechamiento potencial. Se tomará como parámetro los indicadores propuestos por la normativa local. En caso de disponer de una normativa que establezca un límite de crecimiento, se evaluarán con las mismas pautas del punto anterior, los indicadores de sostenibilidad en la situación futura.

e- $\quad$ Indicadores de contexto. Se tendrá en cuenta la localización de la UTC y la accesibilidad a equipamientos, lugares de empleos, etc. para definir las Unidades Territoriales de Análisis (UTA), que permiten identificar el área de influencia y los desplazamientos necesarios para evaluar el grado de dependencia de la UTC.

f- Evaluación comparativa. En función de la bibliografía referenciada y de la experiencia compartida, se definirá una forma de sistematizar la comparación las UTC, tendiendo en cuenta la particularidad de sus localizaciones.

g- $\quad$ Formulación de conclusiones y recomendaciones. De acuerdo a los objetivos del trabajo, se tendrán en cuenta las posibles acciones correctoras para mejorar la sostenibilidad de los casos de estudio, en función con los parámetros definidos en la Agenda 2030 para el Desarrollo Sostenible de las Naciones Unidas.

\section{ANTECEDENTES}

En la presente ponencia, se plantea una propuesta metodológica, que tomando fuentes de origen europeo, propone una revisión de criterios y de técnicas para un crecimiento urbano sustentable en ciudades sudamericanas, que contemple las realidades locales, desde la mirada de investigadores que aportarán sus experiencias en forma colaborativa para generar un producto replicable en dicho contexto.

La iniciativa parte de una experiencia concreta de un proyecto de investigación en curso (al momento de formular la ponencia), titulado "Sustentabilidad de los procesos de crecimiento en el hábitat urbano del Gran Buenos Aires" desarrollado en el marco del Programa UBACyT de la UBA, correspondiente a la programación 2014/17. A pesar de no estar concluido el informe final, se muestran los avances que fueron tomados para el proyecto colaborativo.

El equipo de investigación inicial, está compuesto por profesionales de distintas especialidades, conformando tres grupos de trabajo, para abordar los siguientes aspectos: 1- Urbanos, 2- Confort urbano abordando temas climáticos y naturales y 3 - Confort urbano abordando temas de ruido urbano.

El primer grupo desarrolló los temas de crecimiento de la mancha urbana y su relación con el crecimiento poblacional, estructura urbana, accesibilidad, uso del suelo actual y potencial y equipamiento urbano, que son los principales avances para la nueva etapa investigativa iniciada en agosto de 2017.

El segundo grupo desarrolló aspectos relacionados con el espacio público, profundizando los indicadores relacionados con el confort término y la biodiversidad. El material elaborado se aplicó para el dictado de una 
materia optativa (Gestión sustentable del crecimiento urbano) de la carrera de arquitectura UBA-FADU, durante los años 2016 y 2017.

El tercer aspecto se focalizó en la contaminación acústica, desarrollándose una colaboración con un grupo de investigación que lleva adelante un proyecto denominado "Mapas de ruido y paisaje sonoro en la construcción material y cultural de centros urbanos; contexto, morfología, identidad y diseño como como herramientas de materialización del hábitat", dirigido por el Arq. Mg. Alejandro Giani, quien ha realizado una adaptación de la metodología a los indicadores utilizados por Salvador Rueda para la presente ponencia.

\section{Casos de Estudio}

En el Proyecto UBACYT 2014/17, se seleccionaron dos municipios dentro del Área Metropolitana de Buenos Aires (AMBA), el Municipio de General San Martín (MGSM), ubicado al norte, dentro de lo que se denomina el primer cordón, con un alto nivel de consolidación y el Municipio de Esteban Echeverría (MEE), ubicado al sur, de reciente creación y un dinámico crecimiento, especialmente con barrios cerrados, denominados, de acuerdo a la metodología utilizada, como "Ciudad Jardín".

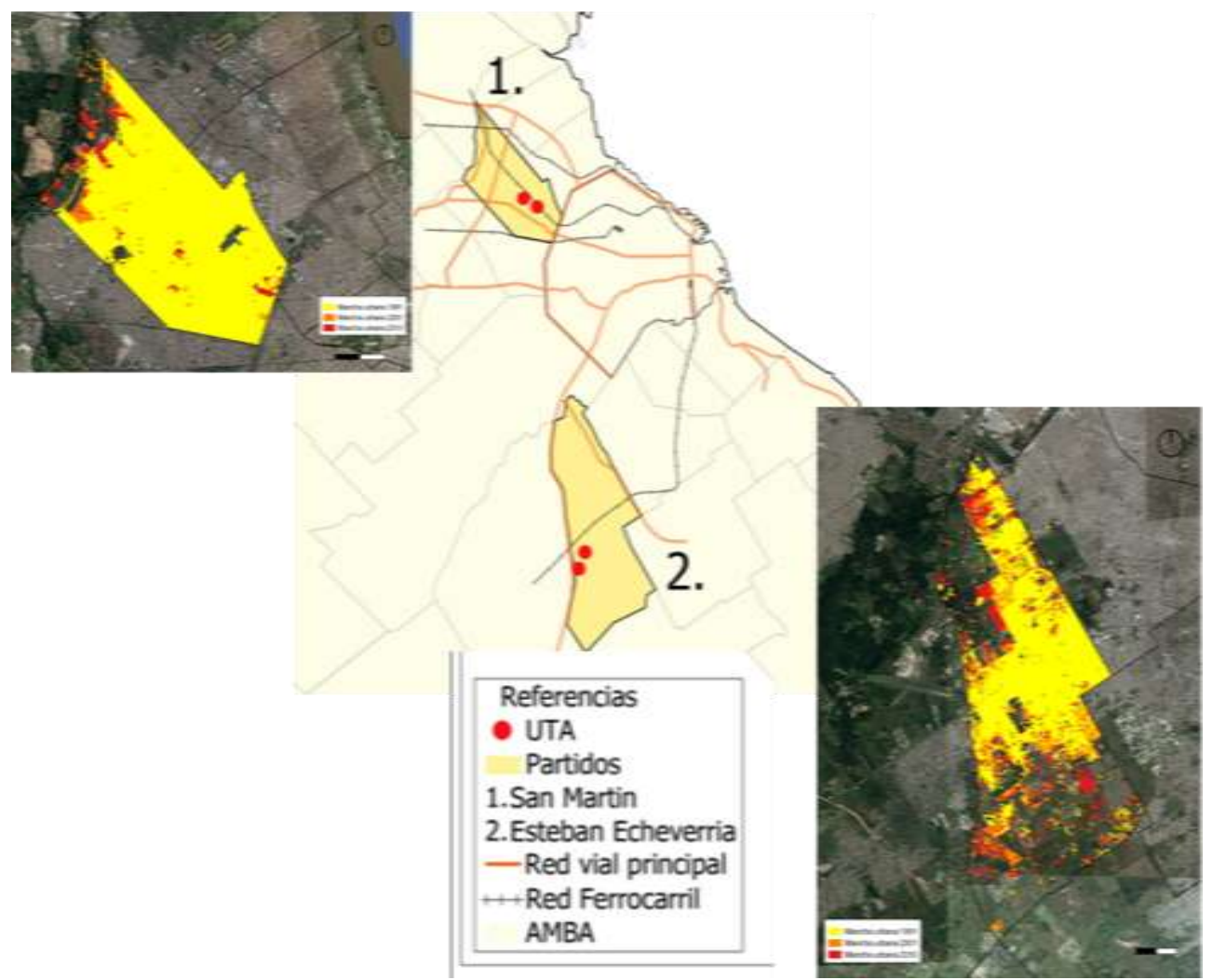

Imagen 1. Ubicación de los casos de estudio y crecimiento de la huella urbana entre 1991 y 2010 en los municipios de San Martín y Esteban Echeverría (Elaboración propia, estudio realizado por la Arq. Alejandra Wagner).

De la lectura de la progresión de la mancha urbana observada en la imagen anterior y su comparación con el crecimiento poblacional en el período 1991-2010, podemos observar que en Esteban Echeverría, la mancha urbana creció un $26 \%$, mientras que la población creció un $53 \%$ y la densidad creció un $21 \%$ (pasó de $44 \mathrm{a} 53 \mathrm{hab} / \mathrm{Ha}$ ). En el caso de General San Martín, en el mismo período, la mancha urbana creció un $6 \%$, mientras que la población creció sólo un $2 \%$, por lo tanto la densidad descendió casi un $4 \%$.

Si sólo se tuvieran en cuenta estos datos, se podría decir que la tendencia de MGSM es más insostenible que la de MEE, pero profundizando en las formas de crecimiento que están ocupando el territorio, cambia y se aclara esta percepción.

\section{Estructura Urbana}

Otro aporte para la nueva etapa de investigación, que permite identificar el contexto urbano de las UTAs, es la definición de la representación de la estructura urbana de las distintas ciudades, con algunos elementos considerados significativos, graficados de la misma manera. Esto permite apreciar la localización relativa de la forma de crecimiento seleccionada, sin conocer en profundidad la ciudad. 

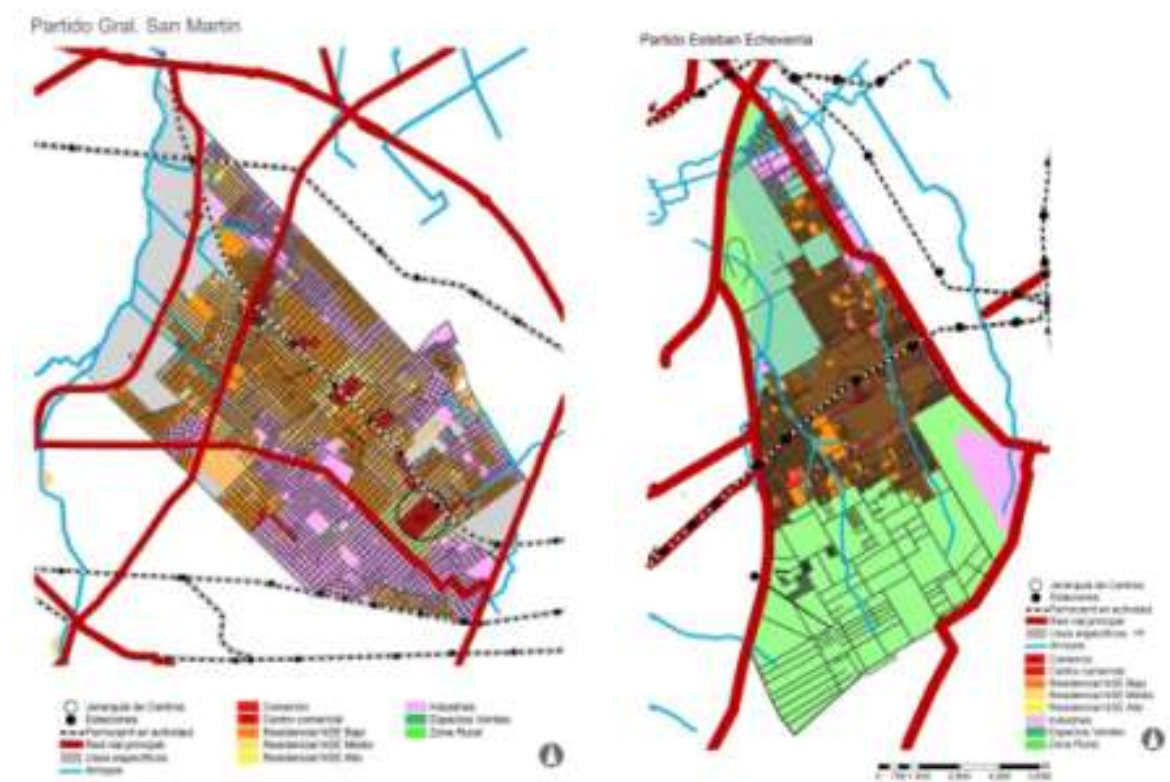

Imagen 2: Estructura Urbana de los Municipios de GSM y EE. Elaboración propia, estudio realizado por la becaria Rocío Zucci en el CIM-UBA-FADU. Aplicando la metodología de Solá Morales, se definieron cuatro UTAs, dos en cada municipio.

En el MGSM, se seleccionaron los siguientes casos:

Ensanche del casco fundacional $(\mathrm{P}+\mathrm{U}+\mathrm{E})$, con etapas sucesivas de parcelamiento, luego de urbanización y finalmente con la edificación de cada parcela.

Polígono (PUE), con una etapa única para el parcelamiento, la urbanización y edificación del conjunto.

En el MEE, se seleccionaron:

Suburbano $(\mathrm{U}+\mathrm{P}+\mathrm{E})$, en el caso seleccionado, se entiende por urbanización a la construcción de una ruta de acceso que da origen a los diversos parcelamientos, pero sin disponer de una infraestructura completa, se van edificando las parcelas. Este un punto merece una adecuación para la aplicación local de esta FCU. Ciudad Jardín (UP+E), son barrios en los cuales se ofrecen parcelas con servicios y luego se edifican. Este FCU también requiere de una adaptación para distinguir los barrios cerrados de los programas sociales de lotes con servicios para sectores sociales de bajos recursos.

Definidas las UTA, se procede al relevamiento de datos para los indicadores. Como ejemplo se exponen los análisis realizados sobre equipamiento urbano y accesibilidad en las distintas localizaciones.

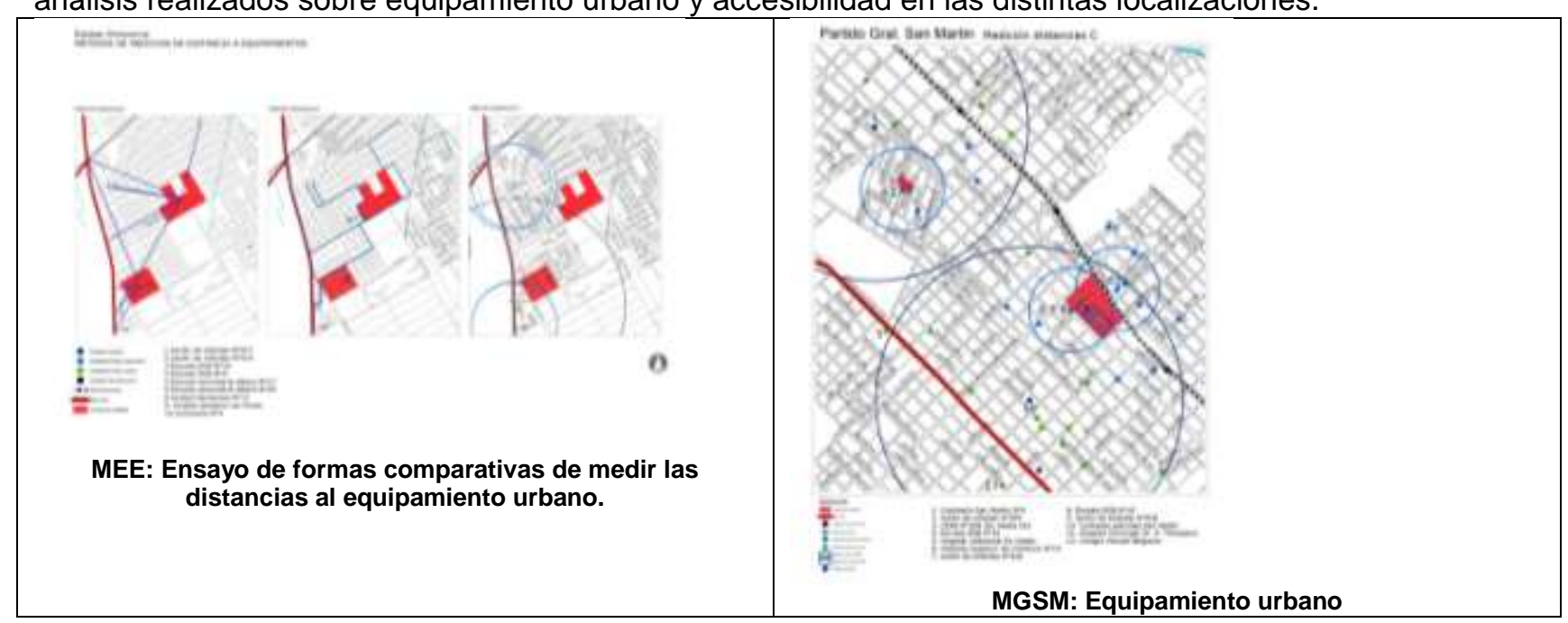




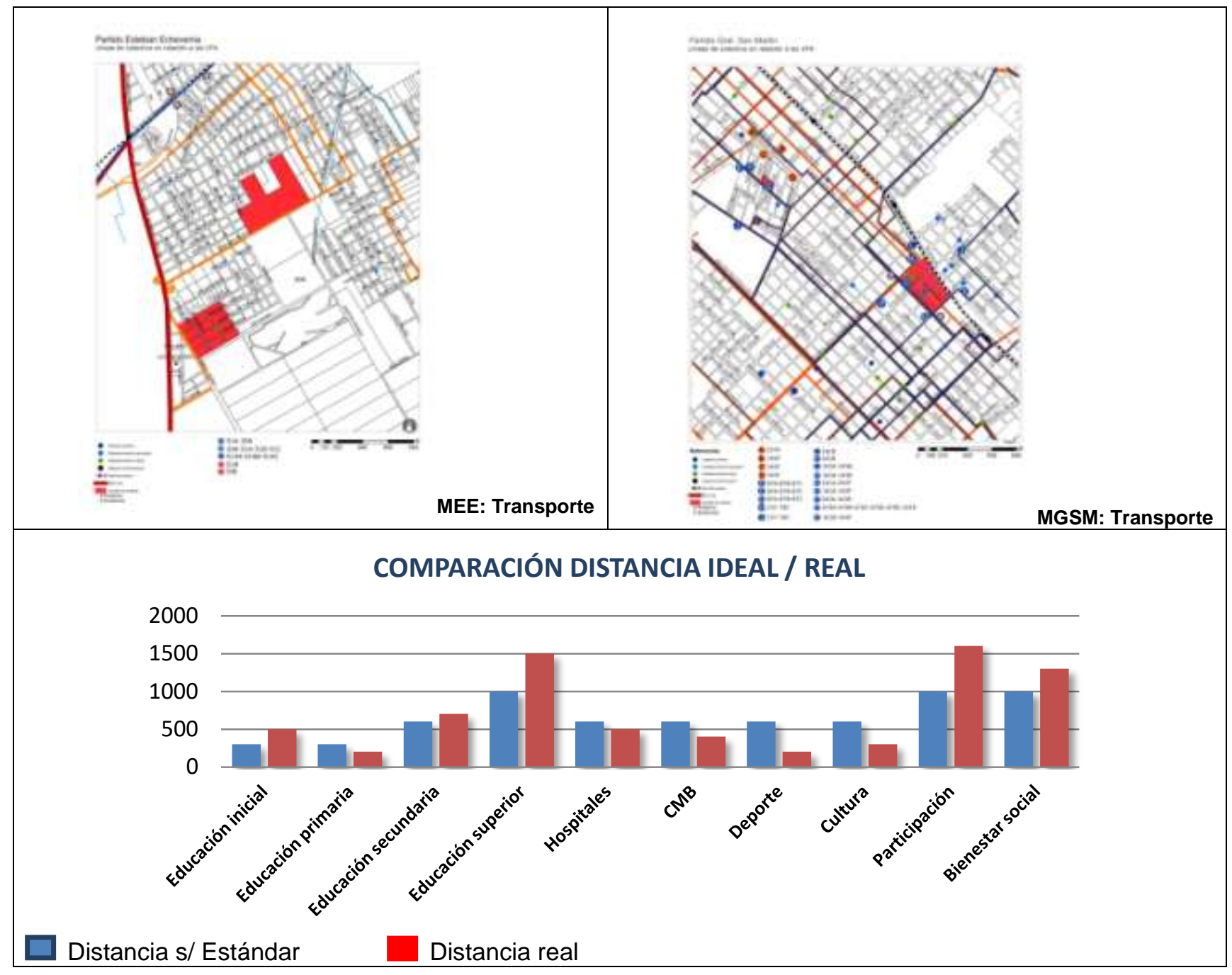

Comparación de los valores que se relevan en los distintos casos, evaluación de diferentes formas de representación.

\section{Confort urbano: Temas climáticos y naturales}

Con respecto a los aspectos climáticos, se realizaron con los alumnos y pasantes, mediciones sobre temperatura, velocidad de viento, etc. $Y$ se simularon situaciones del tejido urbano actual, comparándolo con el tejido potencial que se podría materializar de acuerdo a la normativa urbana del sector. Se presentan algunos ejemplos del trabajo de los alumnos que están siendo procesados para obtener los valores de los indicadores relacionados con el espacio público.
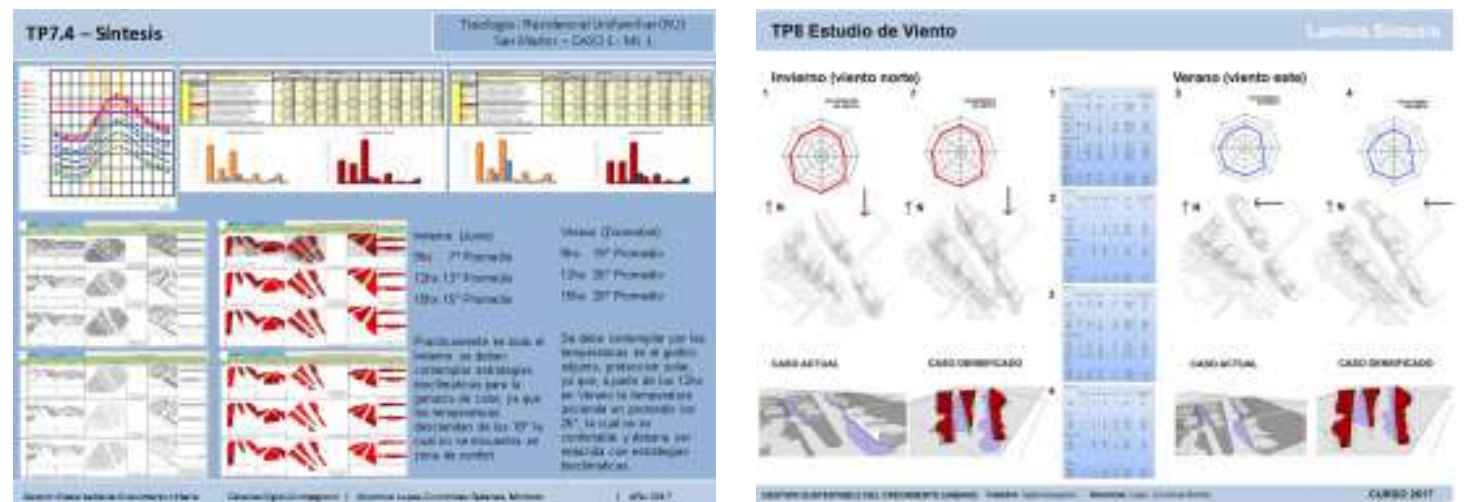

Estudios realizados por alumnos de la materia GSCU-FADU-UBA en 2017. 

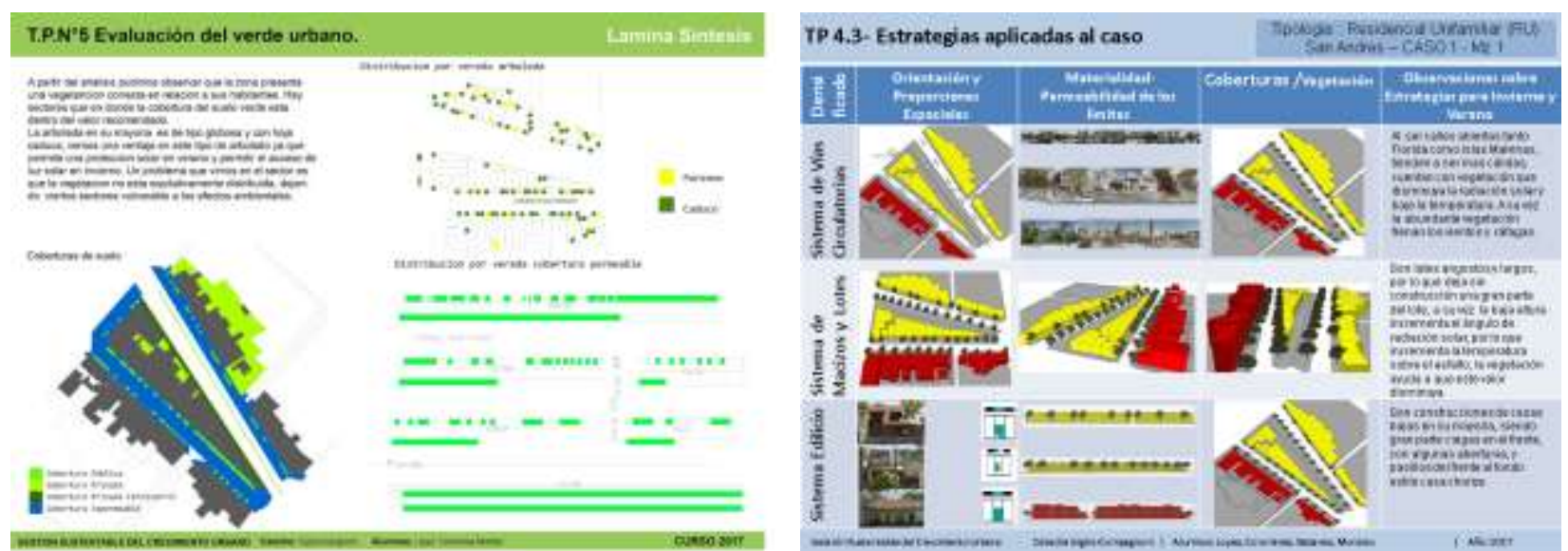

Estudios realizados por alumnos de la materia GSCU-FADU-UBA en 2017.

\section{Confort urbano: Ruido urbano.}

A partir del trabajo realizado durante el año 2017 sobre los recortes urbanos seleccionados; Polígono, C. Jardín, Ensanche y Suburbano, se realizaron mediciones de nivel sonoro con la finalidad de evaluar las condiciones de las UTC seleccionadas desde la perspectiva de los indicadores propuestos a partir de S. Rueda. En particular en lo referente a este tema el Indicador identificado como Confort Acústico y que refiere a tres rangos/valores de referencia como límites de confort/disconfort y porcentajes de población alcanzada por cada uno de estos, de manera de poder puntuar y evaluar dentro de una matriz genérica y que incluye el resto de las variables objeto de estudio.

La tarea se realizó a partir de etapas sucesivas que involucro desde trabajo de campo y relevamiento metrológico hasta su procesamiento y adaptación a la matriz de trabajo. Es estas etapas podrían sintetizarse en las siguientes instancias.

\section{1) Relevamiento de campo}

Para cada una de las UTC seleccionadas se realizaron mediciones de nivel sonoro in situ en lugares representativos de cada cuadra y manzana, de manera de obtener valores reflejantes del "ambiente" acústico de cada sector. En todos los casos las distancias entre puntos de medición fluctuaron entre 50 y $100 \mathrm{~m}$ de distancia entre puntos.

Estas mediciones se realizaron con equipos decibelímetros, midiendo en la escala de ponderación $\mathrm{A}$, a $1,20 \mathrm{~m}$ del suelo y dirigiendo el equipo hacia las vía de circulación/fuente principal de ruido, tomando 5 mediciones o más en cada punto seleccionado. Cada medición estuvo acompañada del conteo del aforo vehicular divididos estos en pesados, livianos y motocicletas, de manera de cuantificar en simultaneo valor emergente y a la vez su origen.
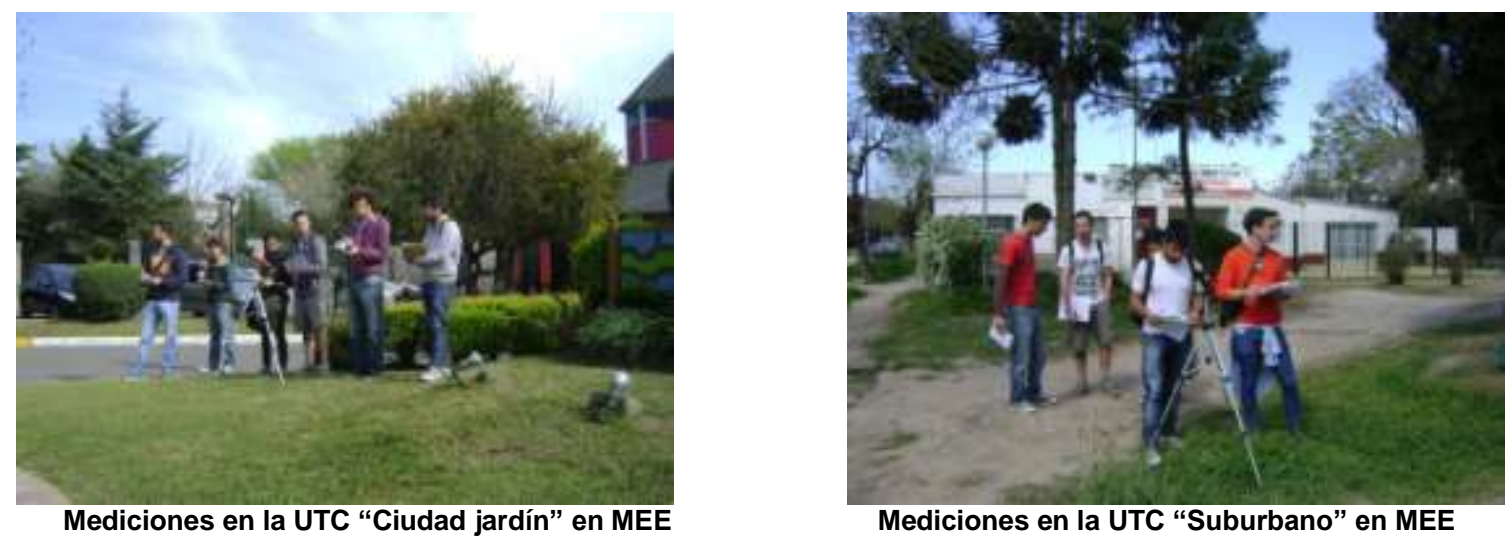


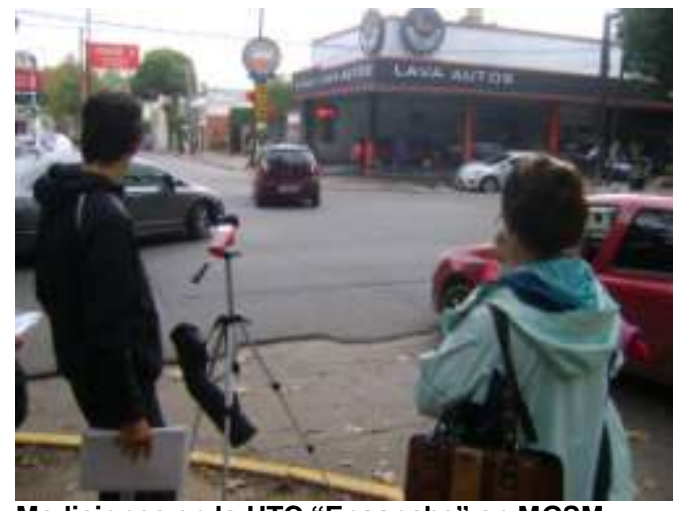

Mediciones en la UTC “Ensanche” en MGSM

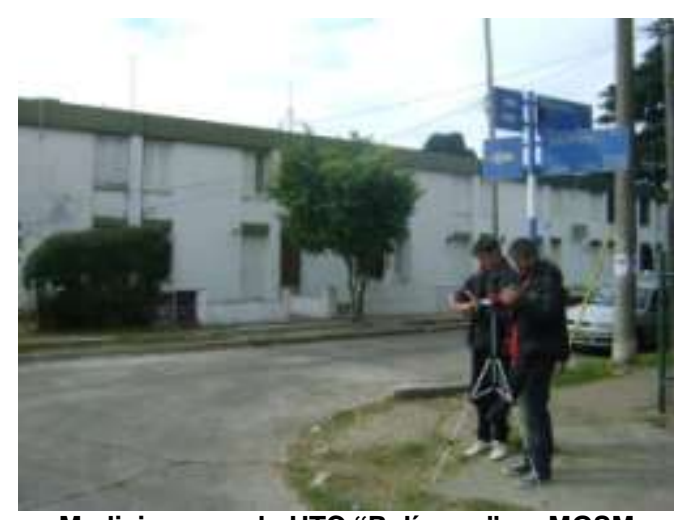

Mediciones en la UTC "Polígono" en MGSM

2) Calculo de los niveles sonoros continuos equivalentes

A partir de las mediciones realizadas y de la repetición de las mismas en cada punto, se realizó el cálculo del valor Leq, y que representa el valor representativo de los anteriores a partir de la integración temporal de cada uno de ellos.

El valor resultante representa el (NSCE) nivel sonoro continuo equivalente en el punto seleccionado y expresado en decibeles.

3) Armado de la cartografía acústica de cada recorte Con la información obtenida de las mediciones y de los valores Leq. Antes descriptos, se realizaron los mapas sonoros de cada UTC, a los que se le aplicó un a escala cromática en saltos de $5 \mathrm{~dB}$.

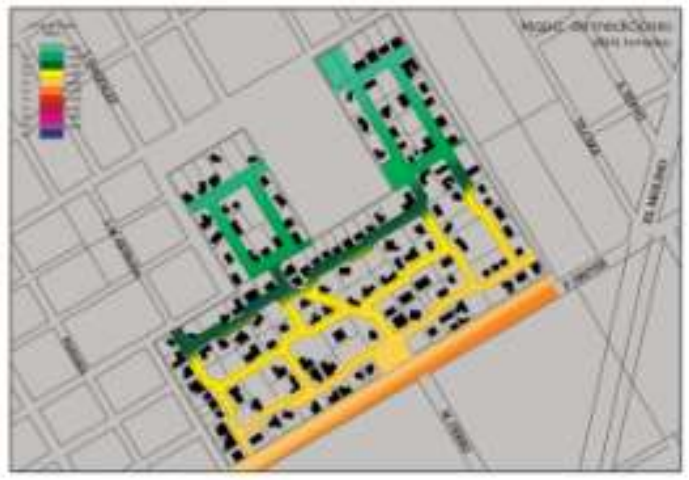

Graficación en la UTC “Ciudad jardín” en MEE

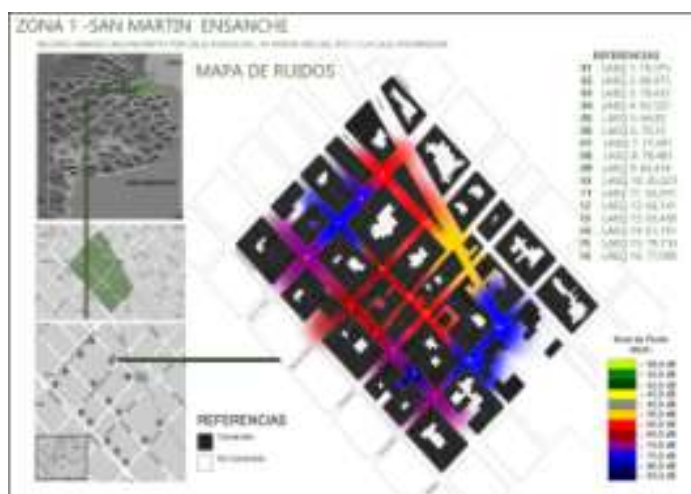

Graficación en la UTC “Ensanche” en MGSM

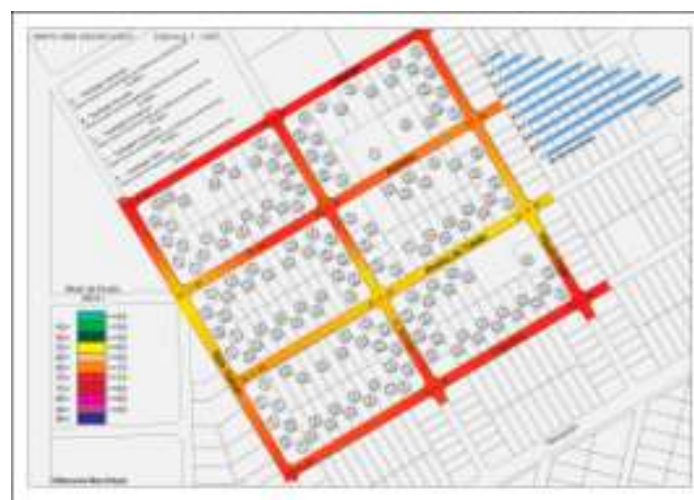

Graficación en la UTC "Suburbano” en MEE

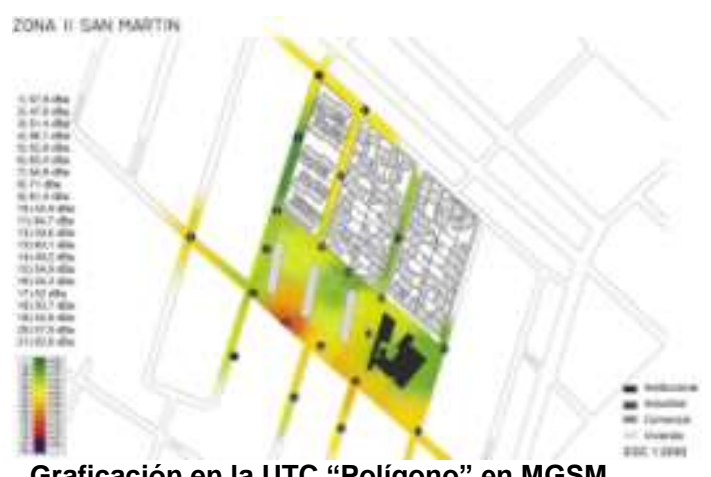

Graficación en la UTC "Polígono" en MGSM

4) Evaluación de los valores resultantes obtenidos y adaptación al indicador El indicador tomado define tres escalas de nivel sonoro como parámetros de análisis; por debajo de $65 \mathrm{~dB}$, entre 65 y $70 \mathrm{~dB}$ y por encima de $70 \mathrm{~dB}$. En paralelo a ello, siguiere una cantidad porcentual de población alcanzada mínima recomendada por estos rangos de perturbación sonora. Así también, contempla dos situaciones, diurna y nocturna, siendo esta última la de mayor exigencia por razones obvias de descanso. 
Sometidos a este esquema de Indicador de Confort Acústico, la resultante provisoria de las cuatro UTC seleccionadas da por resultado el siguiente cuadro resumen;

\begin{tabular}{|c|c|c|c|c|c|c|c|c|c|}
\hline INDICADOR S/RI & & & & & & & & & \\
\hline \multicolumn{10}{|c|}{ CONTAMINACION ACUSTICA } \\
\hline \multicolumn{2}{|c|}{ NIVEL SONORO DIURNO } & \multicolumn{8}{|c|}{ UTAS } \\
\hline \begin{tabular}{|l|} 
NIVEL \\
\end{tabular} & COBERTURA & ENSANCHE & CUMPLE & POLIGONO & CUMPLE & SUBURBANO & CUMPLE & C.JARDIN & CUMPLE \\
\hline$<65 \mathrm{~dB}(\mathrm{~A})$ & $60 \%$ Poblacion & $25 \%$ & NO & $100 \%$ & SI & $28,57 \%$ & NO & $80 \%$ & SI \\
\hline $65-70 \mathrm{~dB}(\mathrm{~A})$ & $15 \%$ Poblacion & $37,50 \%$ & NO & $0 \%$ & SI & $42,86 \%$ & NO & $20 \%$ & NO \\
\hline$>70 \mathrm{~dB}(\mathrm{~A})$ & $25 \%$ Poblacion & $37,50 \%$ & NO & $0 \%$ & SI & $28,57 \%$ & NO & $0 \%$ & SI \\
\hline
\end{tabular}

Según Indicador Confort Acústico y a modo de cierre preliminar se distinguen claramente dos grupos de resultados;

Los dos recortes urbanos que cumplen total o parcialmente el estándar propuesto son el caso del Polígono y el de Ciudad Jardín y que si bien en ambos casos son productos de una urbanización y planificación fruto de una acción proyectual, a la vez ambos podrían considerarse como diferenciados respecto de los discursos de modelos de ciudad que cada uno de ellos exhibe.

Dentro del segundo grupo de UTC y que no han cumplido los parámetros propuestos por el indicador se encuentran el caso del Ensanche y el Suburbano, ambos también diferenciados respecto de sus lógicas de generación y concreción.

En la fecha de presentación de la presente ponencia, se están desarrollando actividades para adaptar los datos elaborados, a los indicadores de AEU, para poder transferir los resultados de la investigación UBACYT 2014-2017 a la nueva etapa colaborativa.

Como ejemplo se agregan las mediciones realizadas utilizando la grilla que propone Salvador Rueda en la UTC correspondiente al Ensanche del MGSM.

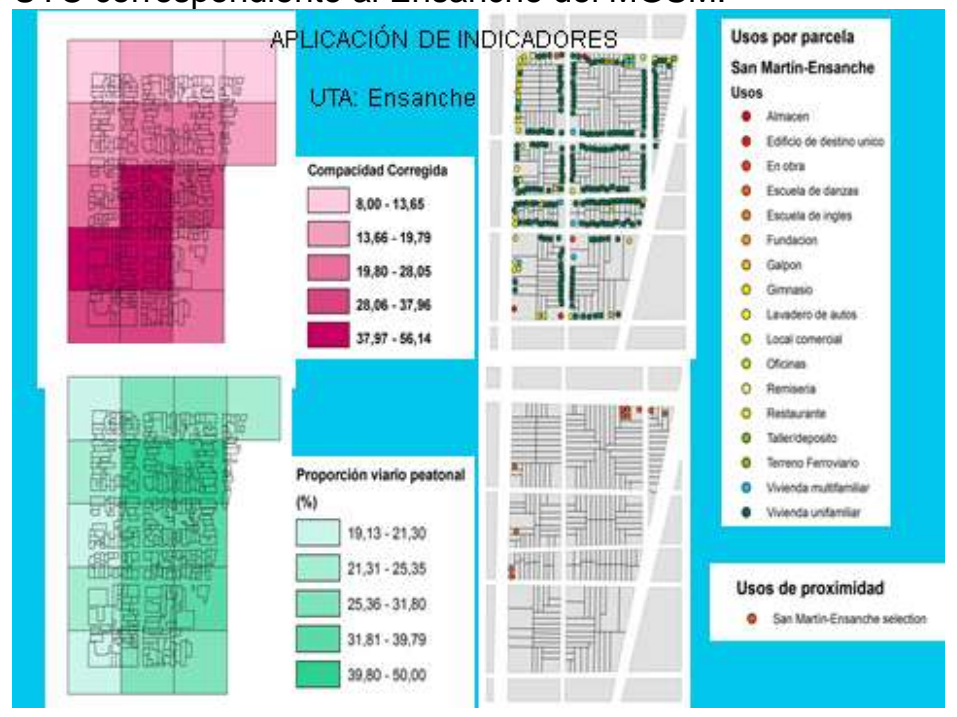

Como aporte de la investigación, se propone que en el caso de las mediciones a realizar a escala de la UTA, no se aplique la grilla de 100X100, propuesta por la AEU, sino que se calculen de acuerdo al sector de estudio, como en el ejemplo siguiente, elaborado por el becario Gabriel Mancuello. 


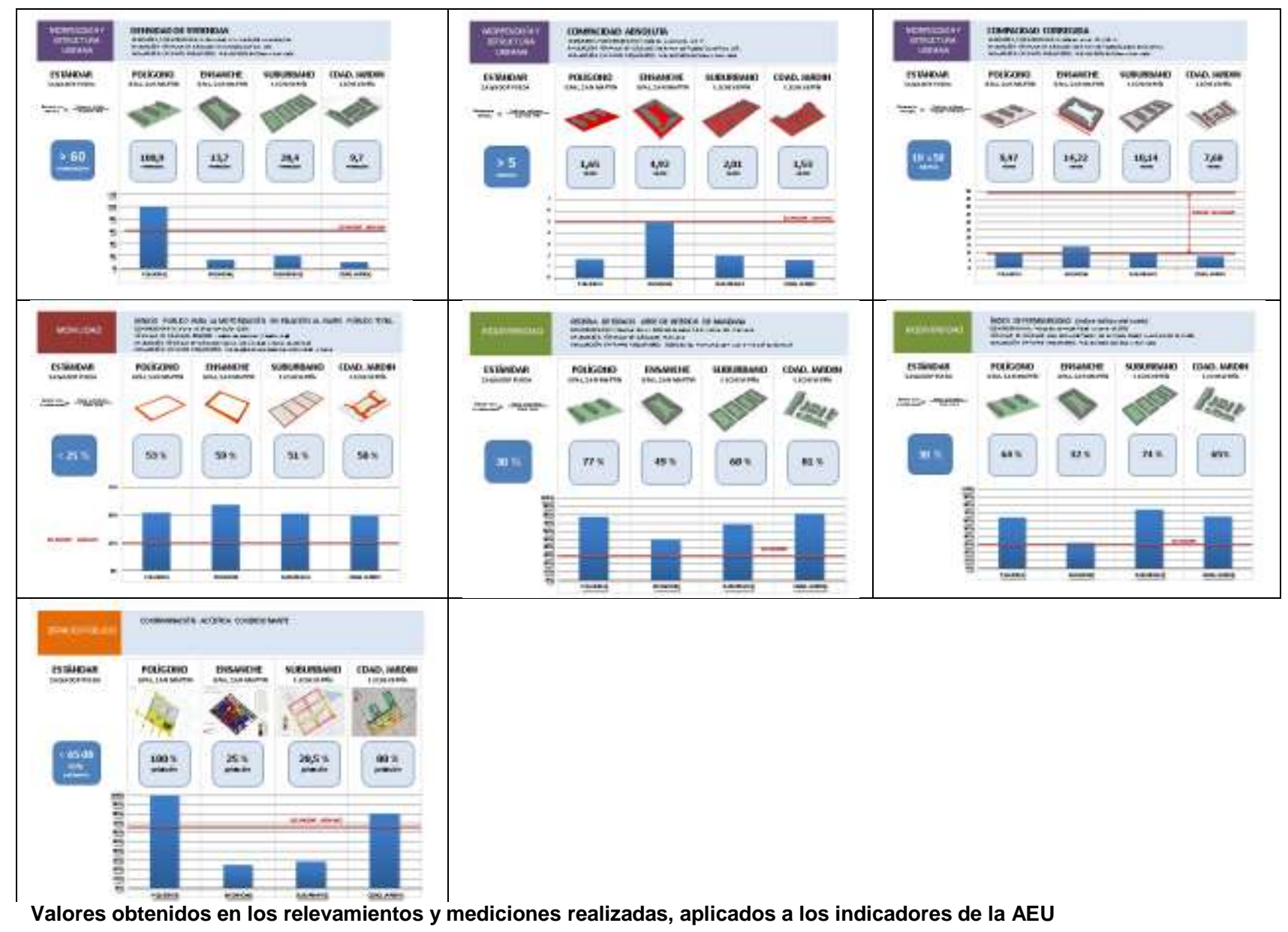

\section{Transferencias}

Dentro de los antecedes que se pueden mencionar, también existen transferencias realizadas a distintos municipios de algunas metodologías aplicadas en la investigación.

Municipio de General San Martín, Provincia de Buenos Aires: Se le entregaron las mediciones de los distintos sectores del municipio, donde los alumnos compararon la situación del tejido urbano actual, con la situación de edificabilidad potencial propuesta por la normativa municipal, elaboradas por los alumnos de la materia optativa Gestión Sustentable del Crecimiento Urbano (GSCU).

Municipio de San Martín de los Andes, Provincia de Neuquén: Se aplicaron las técnicas para la medición de la expansión urbana y su comparación con el crecimiento poblacional para evaluar la sostenibilidad del crecimiento del territorio. Asimismo, se utilizó la metodología de identificación de distintas formas de crecimiento urbano, para identificar el modelo territorial del "Plan Estratégico San Martín de los Andes 2030".
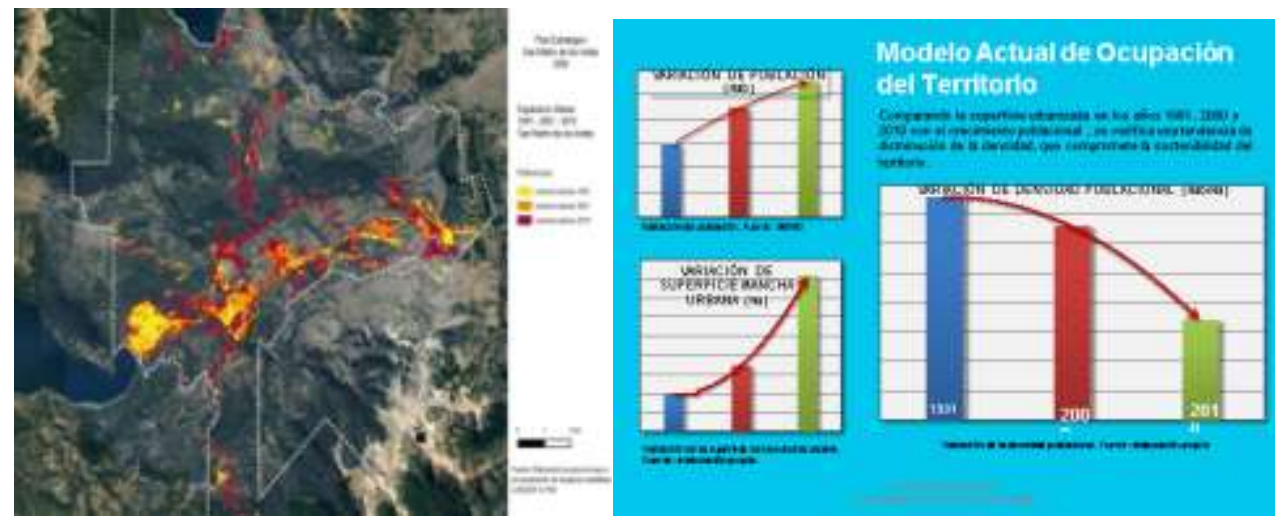

Estudios aplicados al Municipio de San Martín de los Andes, Provincia del Neuquén, Argentina (PESMA2030) 


\section{CASOS DE ESTUDIO}

\section{Colombia:}

Área metropolitana de Bogotá, Localidad de USME. Universidad Antonio Nariño Dir. Elquin Puentes

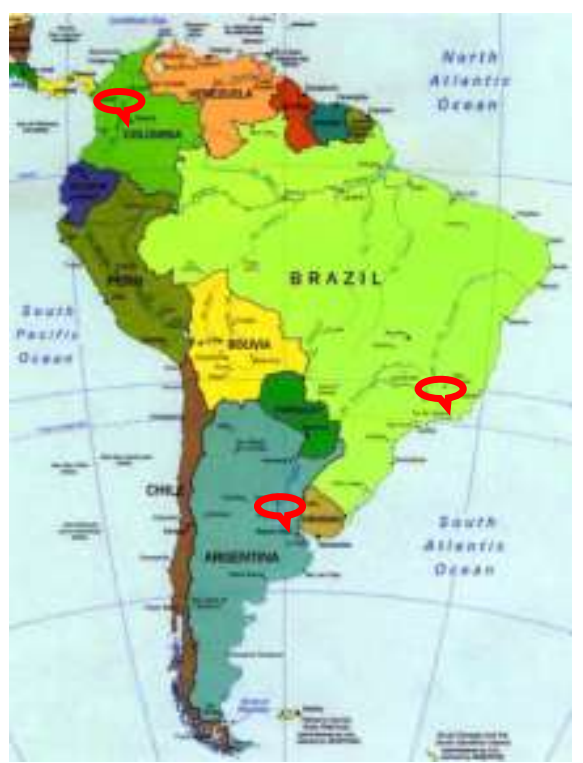

Brasil:

Área Metropolitana de Río de Janeiro. Ciudad de Maricá. Universidad Federal Fluminense. Dir. Werther Holzer

\section{Argentina:}

Municipio Del Pilar, Provincia de Buenos Aires.

Universidad de Buenos Aires. Dir. Mónica Adriana Giglio

\subsection{Colombia}

Área metropolitana de Bogotá, Localidad de USME.

Universidad Antonio Nariño

Dir. Elquin Puentes

La localidad de Usme cuenta actualmente con una superficie de $215.06 \mathrm{~km} 2$ del cual 21.2 kilómetros corresponden a suelo urbano, y cuenta con una población de 340.101 habitantes registrando un crecimiento poblacional del $1.21 \%$ y una densidad residencial de 127 habitantes por hectárea. La población fue fundada en 1650, y se configuró como el centro de una zona rural cercana a Bogotá dedicada a la agricultura y como una zona que históricamente ha surtido de parte importante de los alimentos a la capital. Inicialmente se presentaron conflictos y luchas entre colonos, arrendatarios y aparceros por la tenencia de la tierra, esta situación cambió a mediados del siglo XX cuando se parcelan las tierras que eran destinadas a la producción agrícola para dar paso a la explotación de materiales para la construcción lo cual convirtió a la zona en fuente importante de recursos para la urbanización de lo que es hoy la ciudad de Bogotá, ocupando considerables extensiones del municipio y causando un alto impacto ambiental. En 1972, mediante el Acuerdo 26 el municipio de Usme se incorporó a la ciudad de Bogotá pasando a ser una localidad de la misma. Hasta esa época su crecimiento fue moderado, y su población se concentraba alrededor de su centro fundacional y en los límites con Bogotá.

\begin{tabular}{|l|l|l|}
\hline $\begin{array}{l}\text { Bogotá está } \\
\text { conformada por 20 } \\
\text { Localidades, la } \\
\text { número 5 } \\
\text { denominada Usme es } \\
\text { donde se encuentra } \\
\text { el objeto de estudio } \\
\text { de esta investigación } \\
\text { para el caso de } \\
\text { Bogotá - Colombia. }\end{array}$ \\
Bogotá & $\begin{array}{l}\text { Usme está conformada a su } \\
\text { vez por 7 Unidades de } \\
\text { Planeamiento Zonal - UPZ, } \\
\text { en dos de estas se } \\
\text { encuentran los sectores } \\
\text { identificados según la } \\
\text { teoría de Sola Morales, } \\
\text { Urbanización Marginal } \\
\text { ubicado en la UPZ Alfonso } \\
\text { López, Ensanche y Polígono } \\
\text { ubicados en la UPZ Ciudad } \\
\text { Usme }\end{array}$ \\
Localidad Usme
\end{tabular}




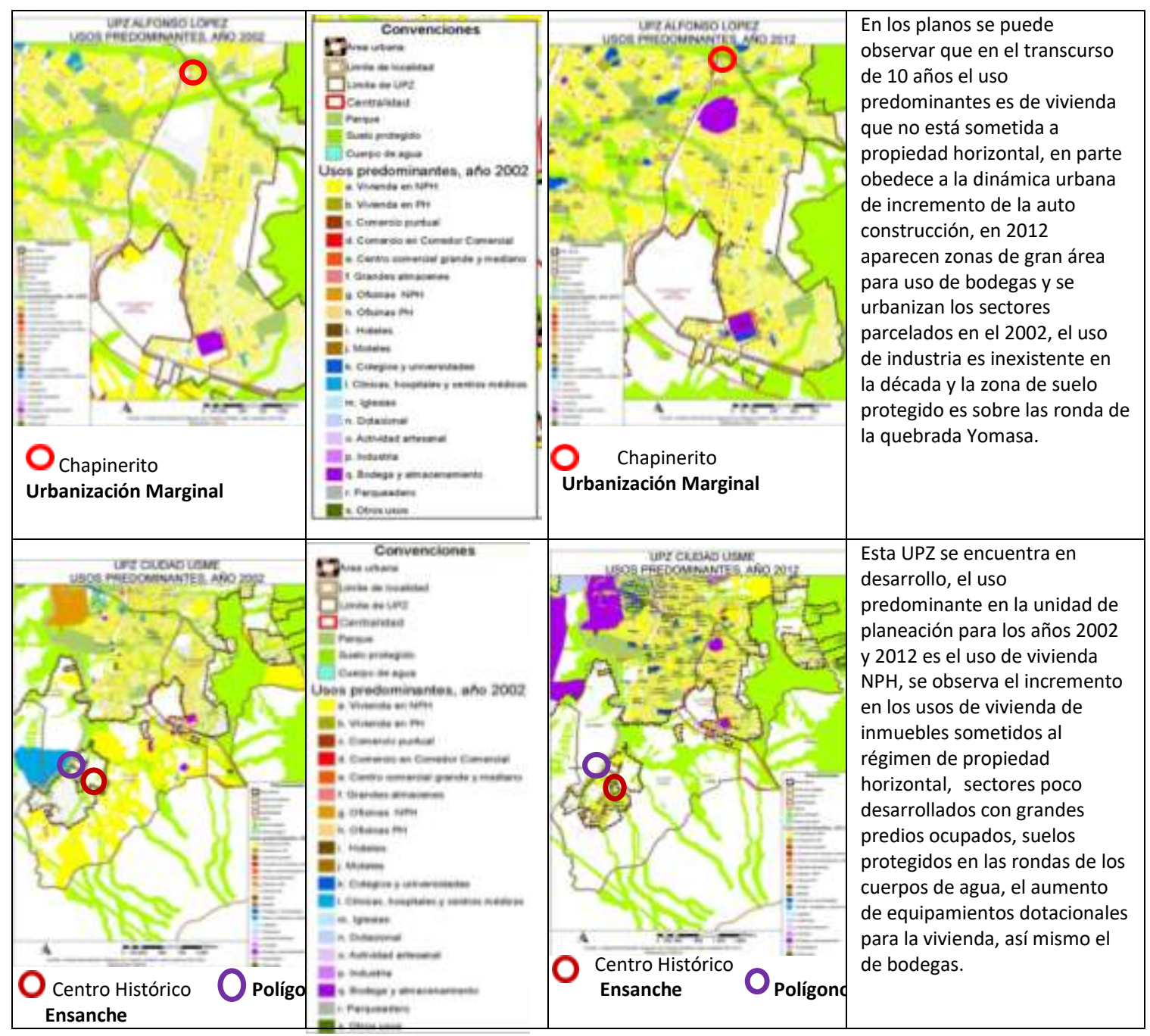

Fuente de los planos: Unidad Administrativa Especial de Catastro Distrital, 2012.

Trujillo, Raúl H, Dinámica de las construcciones por usos de la localidad de Usme en los años 2002 / 2012, 2014.

Para el presente estudio, se han identificado en la localidad de Usme tres Unidades Territoriales de Crecimiento (UTC), de acuerdo a la clasificación que propone Solá Morales sobre formas estructurales de crecimiento: el ensanche, la urbanización marginal, y el polígono. El ensanche, hace referencia a sectores que presentan parcelación, urbanización y edificación que llevan a cabo agentes distintos y de forma no simultánea. Este caso aplica para el casco fundacional de Usme en el cual las tres acciones se han desarrollado de forma no simultánea. (Ver figuras siguientes)
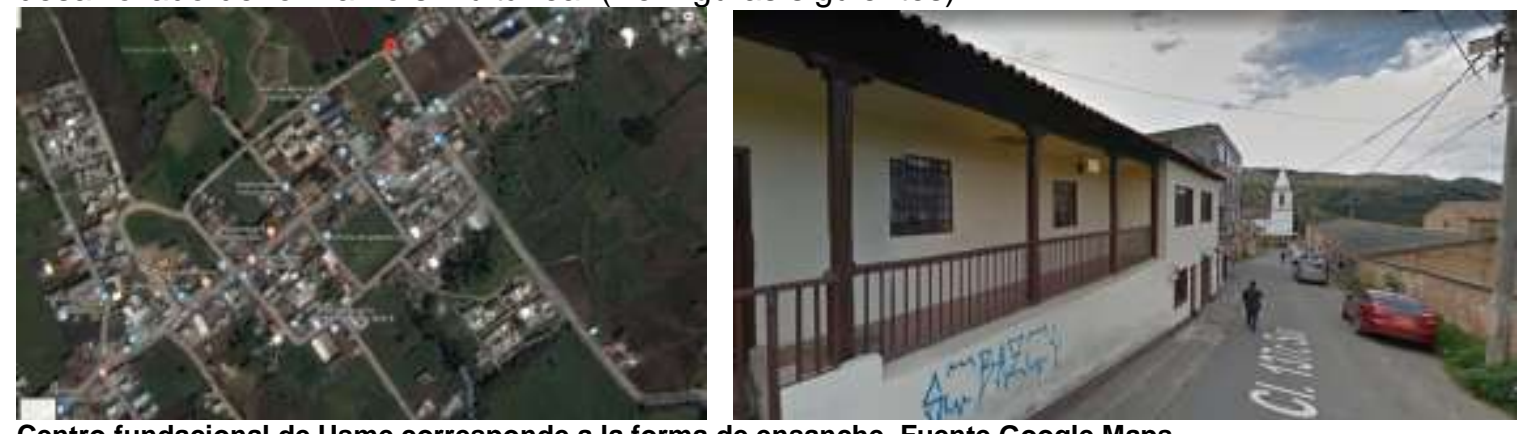

Centro fundacional de Usme corresponde a la forma de ensanche. Fuente Google Maps

En la década de los 70 y 80 se presentan loteos considerados de carácter informal, estos barrios son el resultado de la parcelación de fincas hasta entonces de producción agropecuaria, pero que se fueron urbanizando debido a las presiones demográficas del país y del desplazamiento interno de familias con pocos recursos económicos. Los barrios resultado de estas acciones, se han clasificado como urbanizaciones marginales,(Sola Morales), las cuales se caracterizan por presentar parcelación inicial por parte de un agente, mientras que otro agente edifica, en este caso quienes edifican son los mismos habitantes que han adquirido su lote o parcela; la urbanización viene mucho después, al principio solo se 
trazan las calles, las parcelas no cuentan con servicios públicos ni con títulos legalizados de propiedad, no existen equipamientos ni espacios públicos adecuados. En la década de los 90 en este sector se implementa un programa de Mejoramiento Integral de Barrios, el cual tiene por objeto suplir todas estas necesidades y legalizar estos barrios. En la ciudad de Bogotá dichos programas han causado un gran impacto logrando cifras de gran importancia como por ejemplo la cobertura del $99 \%$ en agua potable. En general se ha incidido positivamente en el mejoramiento de las condiciones de vida de los barrios auto producidos en América Latina ya que han buscado mejores condiciones para quienes las habitan. (Torres 2012), este es el caso del barrio "Chapinerito el cual se propone como caso de estudio referido a la forma de estructural de crecimiento denominada urbanización marginal. (Ver figuras siguientes). Sin embargo esta clasificación debe ajustarse para unificar criterios con el caso de estudio de la ciudad de Buenos Aires, el cual presenta una UTC con características similares, pero se hace una diferenciación en cuanto a lo que se entiende como urbanización, incluyendo calles sin servicios públicos en el caso argentino, a diferencia del caso bogotano donde se ha interpretado urbanización como vías construidas y parcelas necesariamente con servicios. Si se asumiera esta última interpretación, el caso del barrio Chapinerito en Usme podría catalogarse como la forma estructural de crecimiento correspondiente a "Suburbano".
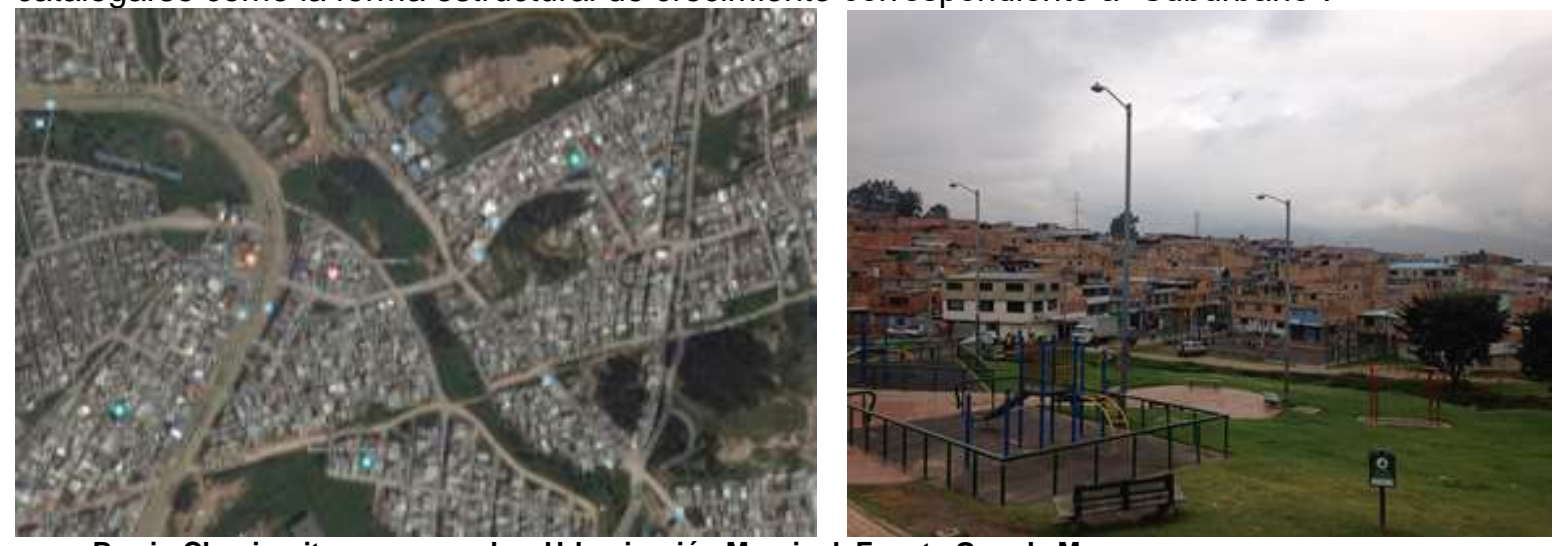

Barrio Chapinerito corresponde a Urbanización Marginal. Fuente Google Maps

El tercer caso de forma estructural de crecimiento, corresponde al denominado Polígono, este corresponde al caso en el cual el mismo agente desarrolla los tres procesos: parcelación, urbanización y edificación, esta tendencia se presenta en el lugar especialmente a partir del año 2000 cuando la alcaldía mayor asume la política de urbanizar y construir vivienda en parcelas baldías antes de que estas fueran invadidas o construidas de manera informal, ello da lugar a varios conjuntos residenciales de los cuales se toman dos para su estudio: metro vivienda Usme y el conjunto Xie. Estos dos casos son relativamente recientes y resultan de interés por tratarse de una forma de crecimiento que no se usaba en el sector y que ha tenido fuertes implicaciones en la manera de insertarse en las estructuras precedentes. Algo que debe confirmarse con el estudio más detallado es la conveniencia de la ubicación del caso del conjunto Xie, pues se presenta desligado del tejido existente y no es del todo clara la incidencia que esto tenga para la aplicación de los indicadores de sostenibilidad urbana en la etapa siguiente del estudio.
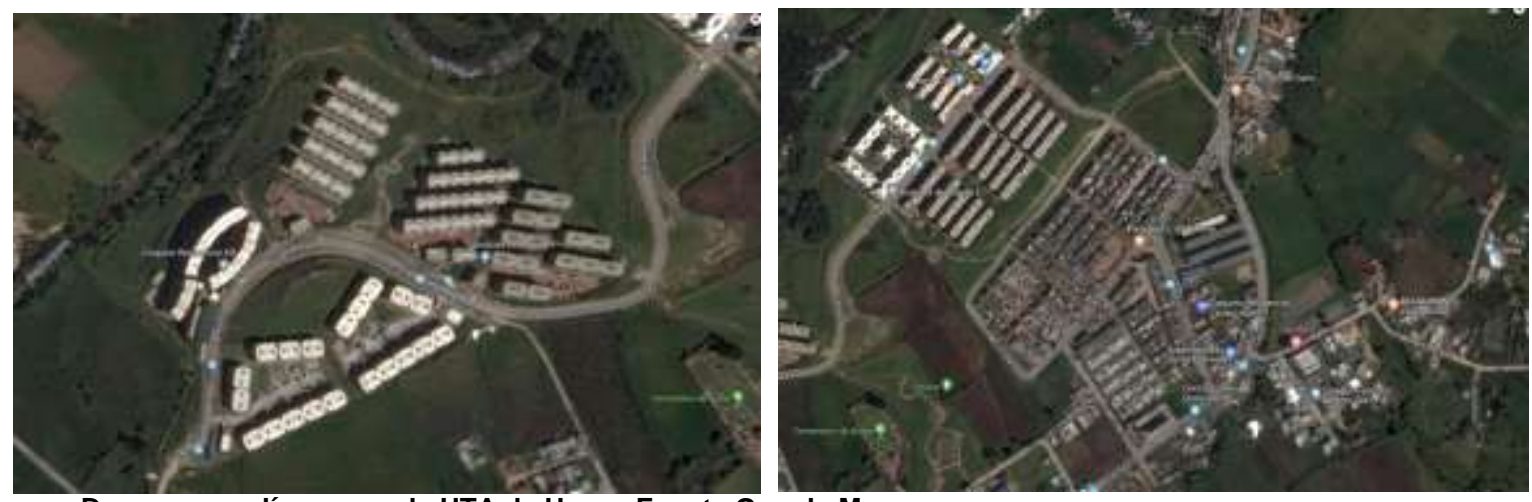

Dos casos polígonos en la UTA de Usme. Fuente Google Maps

A continuación puede observarse como la UTA de Usme se ha modificado en los últimos 17 años, se observan las áreas de mayor crecimiento urbano y las afectaciones a la estructura ecológica principal. 


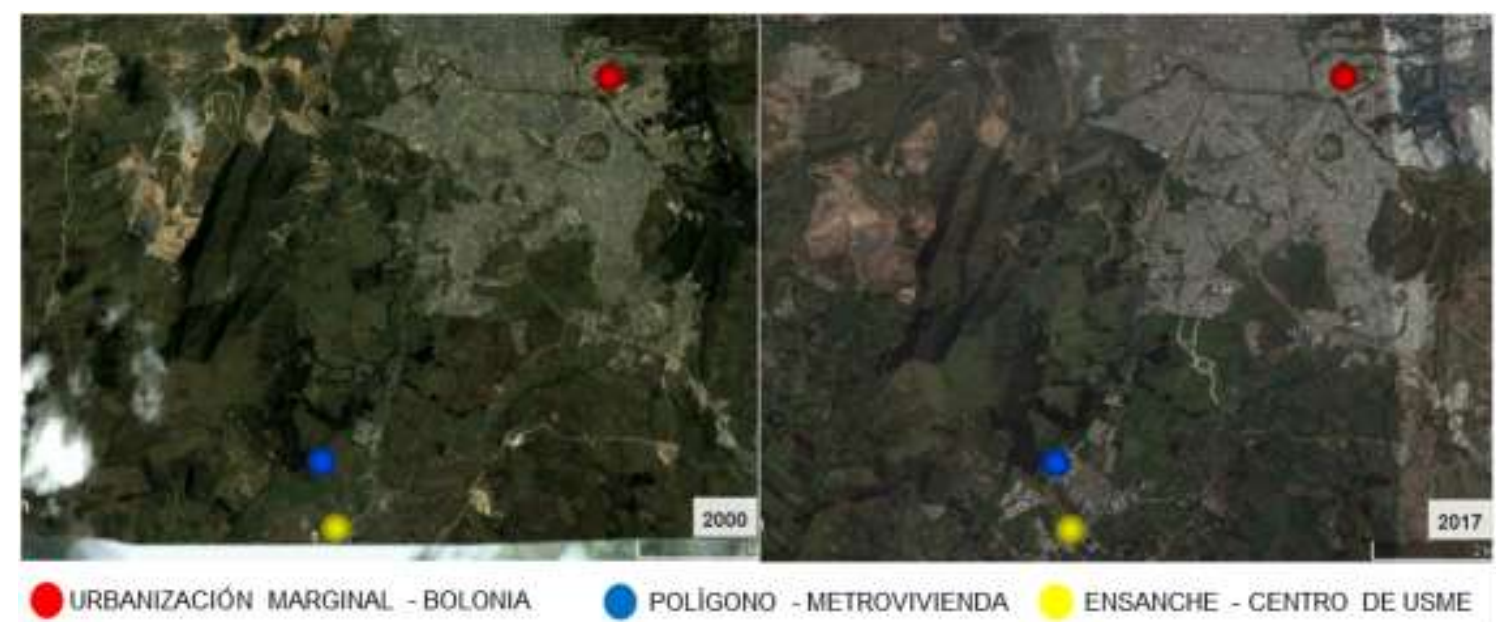

En la figura-----se puede apreciar que la unidad territorial de crecimiento (UTC) presenta cambios a través del tiempo; uno de ellos es la unidad de crecimiento que corresponde al centro de Usme (ensanche), las construcciones presentes como Metrovivienda (polígono) se desarrollaron a partir del 2004 en respuesta a una política de vivienda instaurada en el país para disminuir el déficit de vivienda que se presentaba en ese momento; particularmente en la UTC a pesar de fomentar el crecimiento alrededor del centro (ensanche), la vivienda y los servicios se han ubicado continuamente alrededor del borde urbano (Urbanización marginal Bolonia) que separa a la UTC de la capital de Colombia, lo que demuestra la existencia de un polo de atracción hacia Bogotá y sus municipios vecinos. Otro punto no menos importante es el daño de la estructura ecológica principal de la UTC, lo anterior se aprecia en las imágenes lado izquierdo superior, allí se observa como la extracción de material pétreo para la industria de la construcción ha modificado notablemente el entorno natural de la UTC.

\subsection{Brasil}

Área Metropolitana de Río de Janeiro. Ciudad de Maricá.

Universidad Federal Fluminense.

Dir. Werther Holzer

El objeto de nuestra investigación está ubicado en el área metropolitana de Río de Janeiro, la ciudad de Maricá. La región metropolitana de Rio de Janeiro está conformada por 21 municipios, con una superficie total $6745 \mathrm{~km}^{2}$ e una población estimada en 12330186 habitantes.

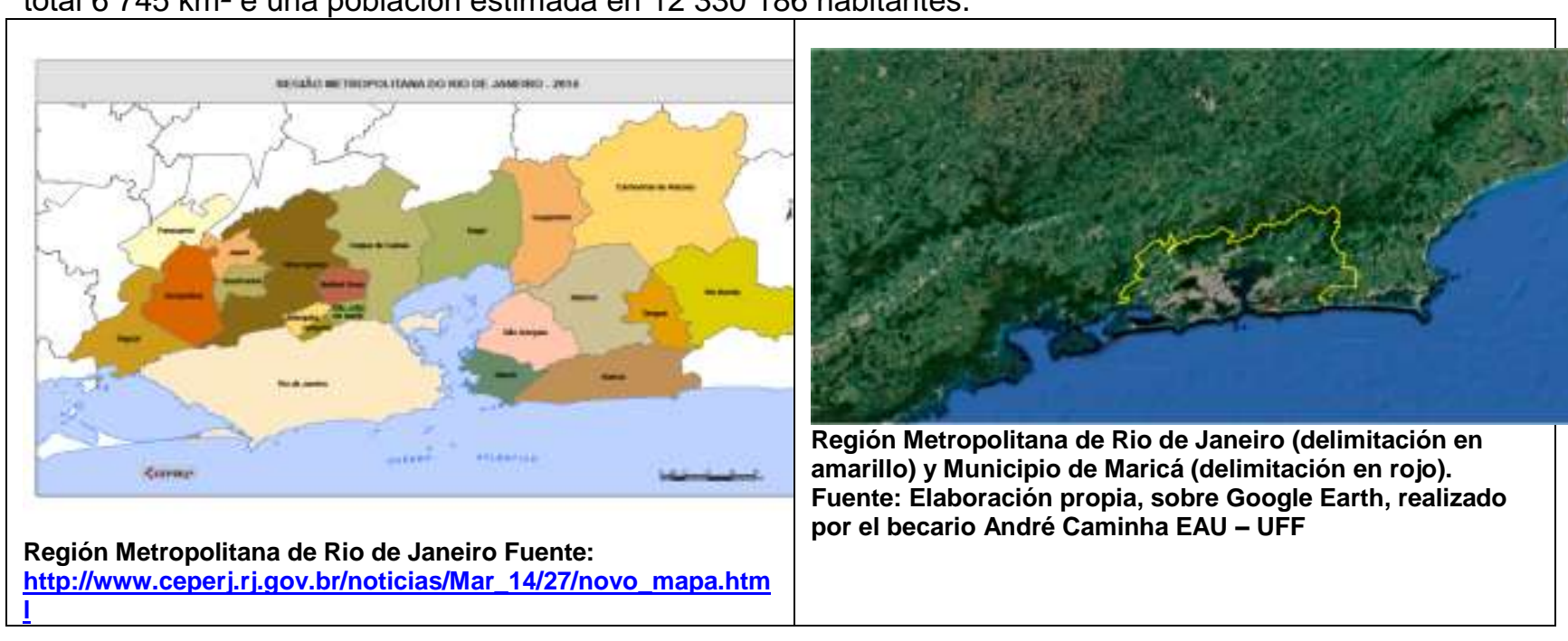

El municipio de Maricá, área de referencia de las Unidades Territoriales de Crecimiento (UTC), tuvo una gran parte de su territorio, con cerca de $350 \mathrm{~km}^{2}$ de los cuales actualmente alrededor de $170 \mathrm{~km}^{2}$ de área urbana, subdivididos a partir de los años 1950. La ciudad, que tuvo sus orígenes en el período colonial (circa de 1650), siempre como un pequeño núcleo que atendía a los productores rurales del entorno, se viene pasando por un proceso acelerado de parcelación desde la década de 1950, aunque su población sólo ha aumentado efectivamente a partir de la década de 1970, manteniendo una media de incremento 
poblacional del orden del 5 al 10\% al año. Actualmente cuenta con una población de unos 150.000 residentes.

A pesar de ese incremento poblacional el stock de lotes vagos se ha mantenido constante en los últimos cuarenta años, con un número estimado entre 100.000 y 150.000 unidades.

La ocupación de este enorme stock de tierras es difícil de evaluar cuando nos referimos a una escala regional. Encontramos un lugar difuso, a lo largo de la carretera, en el que se nos hace difícil encontrar el centro de la ciudad tradicional.

Cuando nos referimos al nivel intraurbano, lo que vemos es un nuevo y complejo proceso de urbanización, con base en los barrios cerrados; condominios rurales; calles privatizadas, a veces considerables porciones de barrios cerrados al uso público; desmembramiento de terrenos con unidades del edificio que intensifican la ocupación de áreas todavía vacías; dispersión del comercio por carreteras estructurales; entre otros.

Estas observaciones nos llevaron a optar por la delimitación de nuestro objeto de estudio utilizando el concepto, enunciado por Reis (2006), de "Urbanização Dispersa" un tipo específico de expansión urbana.

Maricá está conformada por 13 Unidades de Planeamiento - UP, según una ordenación urbana que presentamos en la figura abajo.

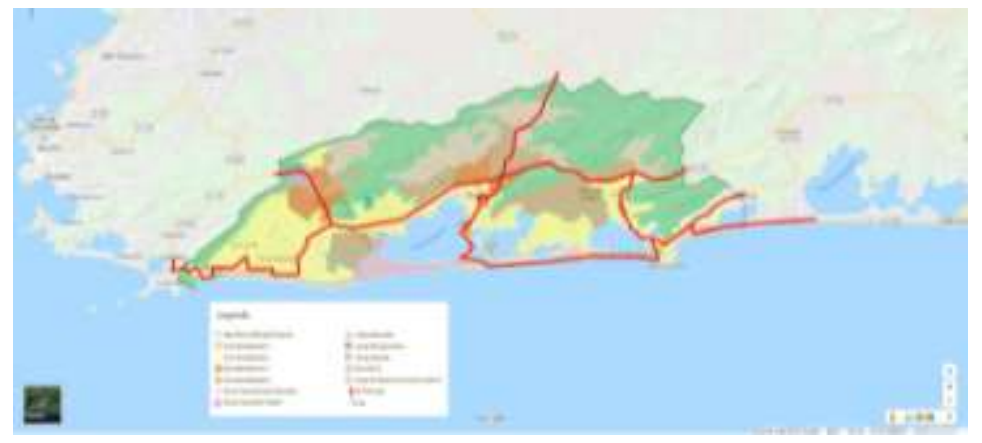

Ordenación urbana de Maricá según el Plan Director y la Ley de uso del suelo municipal. Elaboración propia por el becario André Caminha EAU - UFF

La superficie total de este espacio de dispersión es muchas veces mayor que la ocupada por los centros urbanos tradicionales. Aquí, a diferencia de lo que ocurrió en São Paulo, por ejemplo, más que el esfuerzo del Estado para implementar las industrias, lo que podría generar una dispersión, fueron las parcelas para las residencias de verano que se aprovecharan de esto proceso.

En este caso, las ventajas de localización fueron evaluados por los compradores potenciales desde criterios mucho más subjetivos: la belleza del paisaje, la tranquilidad del entorno, el acceso está restringido, por ejemplo. Aspectos comunes a la segunda y más importante ola de compradores, los que se desvían de los problemas cotidianos experimentados en la gran metrópoli.

En estas áreas la subdivisión de los terrenos, desde el comienzo de su aplicación, se manifiesta un deshilachado de la red urbana, Maricá es actualmente el mejor ejemplo de este fenómeno. Una zona con el centro urbano prácticamente no definida, con muchos tipos de ocupación que interrumpen y se interpenetran, las que llamamos en la investigación de zonas rurbanas, las zonas rurales y las reservas forestales.

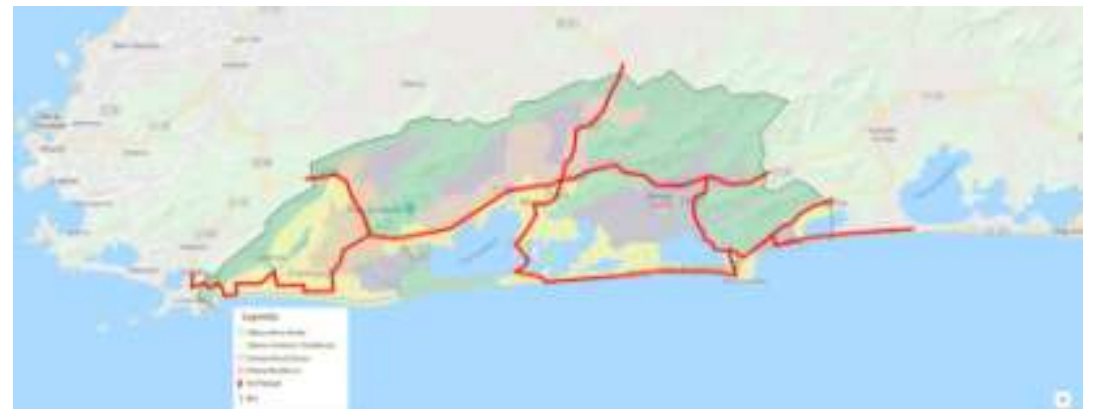


Lo que se intenta en esta investigación es evaluar la aplicabilidad de las Formas de Crecimiento Urbano de Solá Morales en el municipio en cuestión. En este momento de la investigación estamos delimitando las UTC.

Los primeros asentamientos residenciales de la ciudad, también iniciados en los años 40, eran pequeños y confinados a la periferia inmediata de Maricá. De hecho, como identifica Martins (1996), el primer aumento de la fragmentación de la tierra en Maricá se produce en el período de 1950 a 1955. Sólo estos cinco años se registró un aumento de área en de casi $29 \mathrm{~km}^{2}$. Este proceso resultó en una red dispersa de parcelas que involucran al centro urbano propio de Marica, sin causar su crecimiento. A pesar del éxito en las ventas, la gran mayoría de los terrenos no fue ocupada a la vez, y seguiría siéndolo durante décadas.

La década de 1970 estuvo marcada por un nuevo aumento de la especulación sobre la tierra en el municipio. Martins (1996) registró el lanzamiento de 63 parcelaciones en el periodo de 1970-1978, lo que representa un área fraccional de más $36 \mathrm{~km}^{2}$. Este ciclo alcanzó su punto máximo en 1974, con la inauguración del puente Rio-Niterói, también responsable por lo aumento en el número de edificios de residencia de vacaciones.

A partir de esas informaciones puede afirmarse que estas parcelaciones pueden caracterizarse como Unidades Territoriales de Crecimiento -UTC de ensanche.

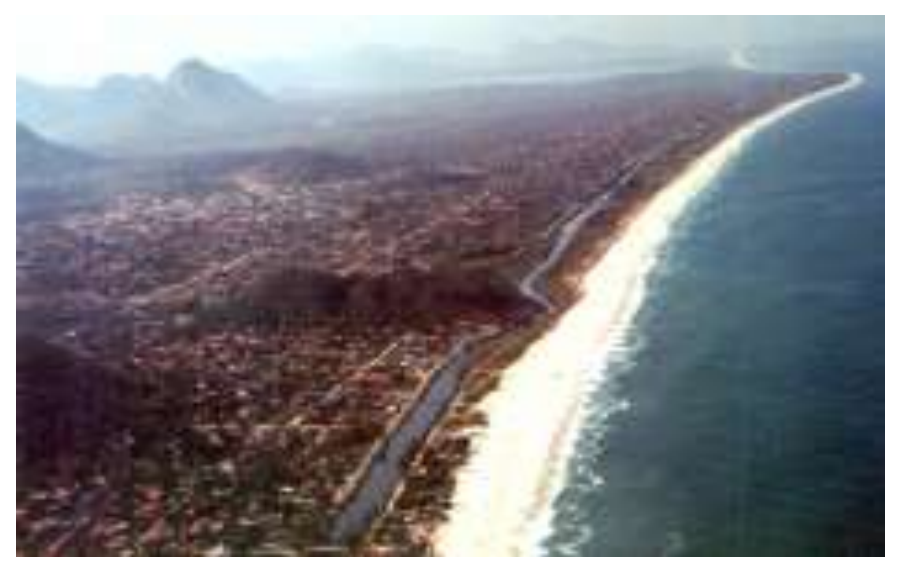

La más grande parcelación de Marica (década de 1950) Jardím Atlântico que puede caracterizarse como una UTC ensanche. Fuente: archivo personal del autor

A principios de los años 80 la ciudad estaba pasando por un nuevo período de estancamiento en el proceso de ocupación de tierras. Sin embargo, la función de suburbio residencial se fortalece cada vez más, un hecho registrado en el crecimiento de la población urbana del municipio. La tasa de la ocupación de las parcelas se hizo más intensa.

Contribuye a este fenómeno de la dispersión en la ciudad el gran stock de áreas vacías. A pesar de esta disponibilidad de áreas para la construcción, el gobierno de la ciudad ha aprobado en los últimos seis años, la concentración parcelaria de estos lotes, que tienen una superficie media de $360 \mathrm{~m}^{2}$ a $450 \mathrm{~m}^{2}$. La principal consecuencia es un engrosamiento de las zonas más valorados, con poco respeto con las áreas libres disponibles en el lote y el impacto en la infraestructura existente, e incluso que se le puede ofrecer en el futuro.

Por otro lado, toda esa área parcelada fue planificada por propietarios privados según los fundamentos teóricos de la ciudad-jardín, de Howard, que dieron origen a los llamados barrios jardín, modificando radicalmente la morfología urbana tradicional con casas alineadas directamente con los paseos de las calles. Se trata de un crecimiento suburbano, pero aún de residencias para vacaciones. Tenemos dudas sobre la ocurrencia de la secuencia propuesta por Sola Morales en el proceso de suburbanización del área, lo que nos motiva a clasificarlas según la UTC ciudad-jardín. 


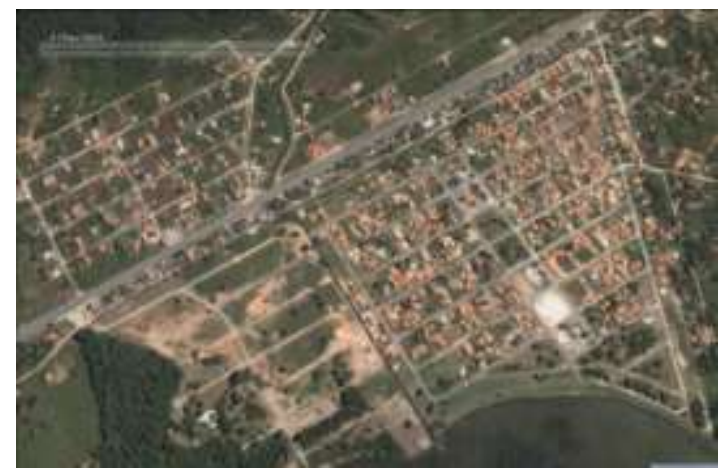

Parcelaciones (Barrios Cerrados) de Maricá caracterizadas como UTC ciudad-jardín. Fuente: Google Earth

Los pequeños emprendedores locales, desde la década de 1990, vieron en la falta de servicios básicos de infraestructura y en el costo relativamente indiferenciado de las tierras disponibles para la parcelación la oportunidad para medir el beneficio ofreciendo al mercado esos pequeños emprendimientos de grupos de viviendas unifamiliares. El principal criterio que orienta la elección del local del emprendimiento es el de adquirir lotes a un precio por debajo del mercado.

Esta opción de implantación que tiene como criterio la construcción en las áreas más baratas disponibles para la venta causó una dispersión de esa tipología de grupos de unidades aisladas por toda la región, sin consideraciones sobre la existencia de cualquier tipo de infraestructura, pues lo que los compradores buscan son atributos bien subjetivos en lo que se refiere a la calidad de vida asociada a la seguridad ya la belleza del local.

Como ya discutido en otro texto el Programa "Mi Casa Mi Vida", subsidiado por el gobierno federal otorgó a los emprendedores inmobiliarios la provisión pública de vivienda. De este modo el control del uso del suelo ejercido por el Estado, aunque poco actuante en la provisión de viviendas sociales con ubicaciones servidas por servicios públicos, fue dejado por cuenta de la iniciativa privada. "(Holzer, 2016). Estos subsidios asociados a otros como el crédito a largo plazo para la compra de vehículos automotores populares y el Programa "Mi Casa Mejor", para la adquisición de muebles, electrodomésticos y ordenadores, hicieron los inmuebles atractivos independientemente de su ubicación favoreciendo la dispersión urbana deslocalizada con respecto a la accesibilidad y los servicios públicos. Muchas de estas áreas pueden ser identificadas como la UTC polígono.

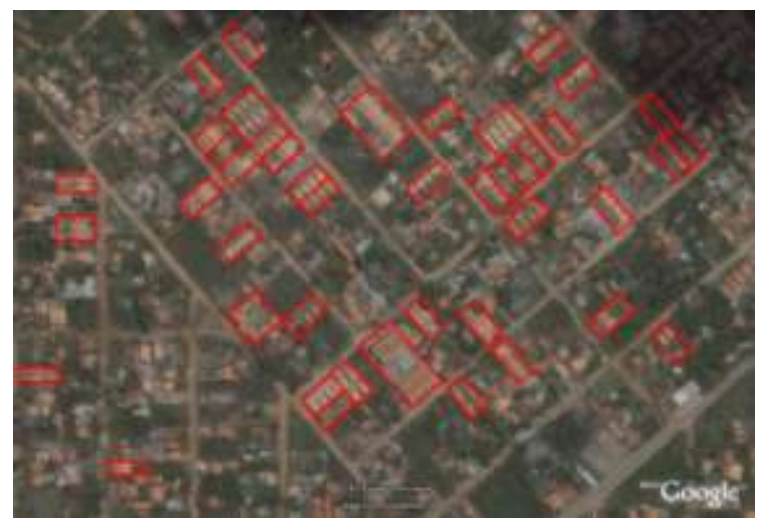

Agrupamientos de unidades de habitación (destacados en rojo) construidas bajo el programa "Minha Casa Minha Vida" que pueden caracterizarse como la UTC polígono. Fuente: Elaboración propia, sobre Google Earth, realizado por la becaria Natalia Antonio EAU - UFF

Aparentemente este procedimiento favorece la concentración de zonas densamente pobladas en lugares privilegiados, en términos de comercio y servicios que se ofrecen en los alrededores. Un tipo de despliegue que facilitaría la expansión urbana. En realidad, lo que se ve es que este procedimiento está potenciando la expansión urbana (Urbanização Dispersa) de la ciudad, es decir, muchas de esas áreas pueden clasificarse como UTC de urbanización marginal.

Otro factor es la dispersión de los barrios cerrados. Los primeros de Maricá que datan de los años 80 , identificados como pequeños lotes de tierra restringidos. Este proceso se intensifica la próxima década, cuando la ciudad decide aprobar proyectos de este tipo, con toda la infraestructura desplegada. De 1990 a 2010 se aprobó cerca de 100 barrios cerrados en la ciudad, con áreas que van desde $5.000 \mathrm{~m}^{2}$ a casi $1.000 .000 \mathrm{~m}^{2}$. Estos también identificamos con la UTC ciudad-jardín. 
Sobre las UTCs barraca y invasión, creemos que se confunden. Se necesitan más estudios para verificar si pueden ser identificadas como ocurrencias distintas. Ocurren, en el municipio, pero aún de modo poco significativo.

\subsection{Argentina}

Municipio Del Pilar, Provincia de Buenos Aires.

Universidad de Buenos Aires.

Dir. Mónica Adriana Giglio

El lugar donde se desarrollará el análisis de casos, es el Municipio Del Pilar, que se encuentra en el borde exterior, al norte del Área Metropolitana de Buenos Aires. La parte sur del territorio municipal tiene condiciones de continuidad con el AMBA, pero la propuesta es mantener la diferenciación de los sectores urbanos y consolidar las centralidades históricas, poniendo límites al continuo urbano difuso y a la fragmentación de las urbanizaciones cerradas.

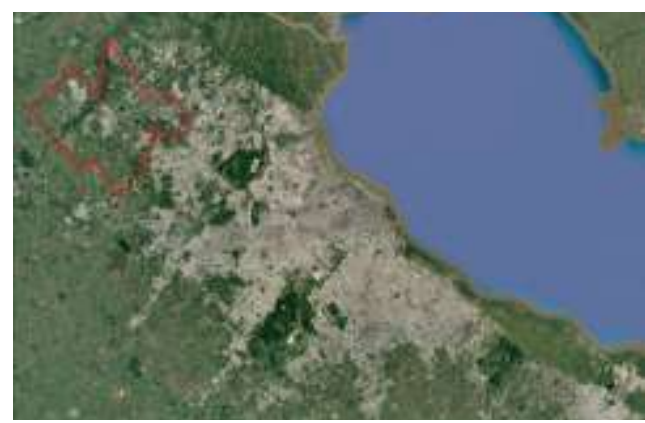

Área Metropolitana de Buenos Aires, ubicación del Municipio Del Pilar

Tiene una superficie aproximada de $355 \mathrm{Km} 2$, y dispone de una superficie urbanizada de unos $150 \mathrm{Km} 2$. La población al año 2010, era de unos 300.000 habitantes y el crecimiento intercensal 2001-2010, fue del $28,7 \%$, según el Instituto Nacional de Estadística y Censos.

La densidad residencial se estima en $8,4 \mathrm{hab} / \mathrm{Ha}$.

Una de las características de este municipio es que una cuarta parte del territorio se encuentra ocupado por urbanizaciones cerradas, en este estudio denominadas "Ciudad Jardín".

El municipio dispone de un Plan y normativa urbanística recientemente elaborada por un convenio con la UBA, aprobada por el Consejo Deliberante Local.

No se han definido hasta esta instancia las unidades territoriales que se van a estudiar, pero continuando con la experiencia anterior, se definirá un "Polígono", una "Ciudad Jardín", un sector "Suburbano" y un sector de "Ensanche", todos dentro del mismo municipio.
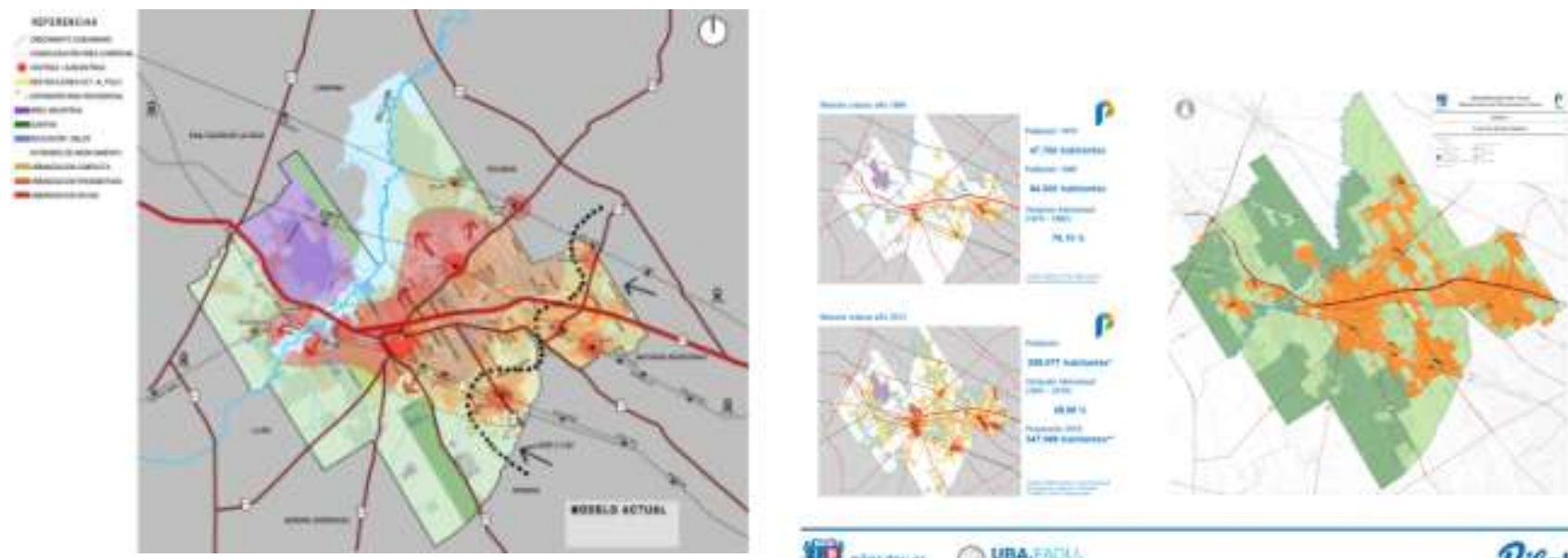

Municipio Del Pilar: Modelo territorial actual, crecimiento urbano y área urbanizada. 


\section{ESTADO DE AVANCE DE LA INVESTIGACIÓN}

Hasta el momento de realizar la presente ponencia, se han definido las ciudades donde se desarrollarán los estudios, y cada grupo de investigación se encuentra identificando las unidades territoriales de crecimiento.

Se está avanzando en la adecuación de la definición de las formas de crecimiento urbano, para su implementación en el contexto sudamericano, redefiniendo las etapas de urbanización del suburbano, para distinguir la urbanización inicial $U$, del completamiento de servicios que se da posteriormente, definiendo el proceso como: $(u+P+E+u)$.

De esta manera, se evalúa la posibilidad de plantear una "U" (urbanización completa) y una "u" (urbanización parcial), así como una "P" de parcelamiento escriturado, por un "p" de parcelamiento sin escritura formal y la diferenciación entre una "E" de edificación consolidada, por una "e", de edificación en consolidación.

Esta adecuación permite definir los procesos de urbanización de nuestras ciudades, en etapas más prolongadas que en Europa.

Asimismo se está reelaborando la forma de obtener los datos propuestos en la metodología de Salvador Rueda, reemplazando la grilla del territorio de 100x100 o 200x200, por las unidades territoriales de crecimiento (UTC) y definiendo los indicadores aplicables en función de las características locales.

Dentro de los resultados de la investigación, corresponderá formular una propuesta de redefinición de los estándares para ajustarlos a la realidad sudamericana.

\section{BIBLIOGRAFÍA}

CEBRIAN ABELLÁN, F., PANADERO MOYA, M. (2013) Ciudades medias. Formas de expansión urbana. Madrid: Siglo XXI.

GARCÍA LANZA, J. (1999) El perfil urbanístico de los Municipios. Madrid: Instituto juan de Herrera.

HOLZER, W (2016). A Urbanização Dispersa e Seu Incremento Pelo Programa "Minha Casa, Minha Vida": O Caso de Maricá - RJ. In: Ojima, Ricardo; Marandola Jr, Eduardo.. (Org.). Dispersão urbana e mobilidade populacional: implicações para o planejamento urbano e regional. 1ed.São Paulo: Ed. Edgard Blucher.

MARTINS, A. M. M. (1996). O parcelamento da terra no município de Maricá, estado do Rio de Janeiro. Dissertação (Mestrado em Planejamento Urbano e Regional), UFRJ (IPPUR), Rio de Janeiro.

REIS, N. G. (2006). Notas sobre urbanização dispersa e novas formas de tecido urbano. Via das Artes, São Paulo.

ROJAS, E. (2009). Construir ciudades, Mejoramiento de barrios y calidad de vida urbana. Montevideo: Banco Interamericano de desarrollo.

RUEDA, S. El urbanismo ecológico. Un nuevo urbanismo para abordar los retos de la sociedad actual. Barcelona: AEU.

RUÍZ, M., y MICHAEL K.(2003). Programas de Mejoramiento Barrial como una estrategia de prevención de violencia. Bogotá: Seminario de Mejoramiento Barrial quince años SUM Consult.

SOLÁ MORALES i RUBIÓ, M. (1997) Las formas de crecimiento urbano. Barcelona: UPC.

TERRAZA, H.,RUBIO BLANCO, D., VERA, F. (2016) De ciudades emergentes a ciudades sostenibles. Comprendiendo y proyectando las metrópolis del siglo XXI. Santiago de Chile: BID.

TORRES, C. (2009). Procesos Urbanos Informales y Territorio. Bogotá: Universidad Nacional de Colombia. 